Article

\title{
Integrated into Environmental Biofilm Chromobacterium vaccinii Survives Winter with Support of Bacterial Community
}

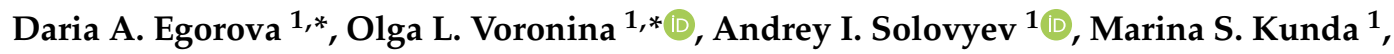 \\ Ekaterina I. Aksenova ${ }^{1}$, Natalia N. Ryzhova ${ }^{1}$, Ksenya V. Danilova ${ }^{1}$, Valentina S. Rykova ${ }^{1}$, \\ Anastasya A. Scherbakova ${ }^{1}$, Andrey N. Semenov ${ }^{1}$, Nikita B. Polyakov ${ }^{1,2}$ (D, Daniil A. Grumov ${ }^{1}$, \\ Natalia V. Shevlyagina ${ }^{1}$, Inna V. Dolzhikova ${ }^{1}$, Yulia M. Romanova ${ }^{1,3}$ and \\ Alexander L. Gintsburg 1,3 \\ 1 N.F. Gamaleya National Research Center of Epidemiology and Microbiology, Ministry of Health, \\ 123098 Moscow, Russia; dronnias@gmail.com (A.I.S.); markunda99@gmail.com (M.S.K.); \\ aksenova16@yandex.ru (E.I.A.); rynatalia@yandex.ru (N.N.R.); kseniya.2494.danilova@gmail.com (K.V.D.); \\ valentinarycova@inbox.ru (V.S.R.); nas.scherbakova99@bk.ru (A.A.S.); semenov_an91@mail.ru (A.N.S.); \\ polyakovnb@gmail.com (N.B.P.); grumovda@gmail.com (D.A.G.); nataly-123@list.ru (N.V.S.); \\ i.dolzhikova@gmail.com (I.V.D.); genes2007@yandex.ru (Y.M.R.); gintsburg@gamaleya.org (A.L.G.) \\ 2 Vernadsky Institute of Geochemistry and Analytical Chemistry of Russian Academy of Sciences, \\ 119991 Moscow, Russia \\ 3 Sechenov First Moscow State Medical University of the Ministry of Health of the Russian Federation, \\ 119991 Moscow, Russia \\ * Correspondence: egorova.daria@gamaleya.org (D.A.E.); olv550@gmail.com (O.L.V.); \\ Tel.: +7-985-312-53-30 (D.A.E.); +7-916-224-86-83 (O.L.V.)
}

Received: 11 September 2020; Accepted: 29 October 2020; Published: 30 October 2020

\begin{abstract}
Chromobacterium species are common in tropical and subtropical zones in environmental samples according to numerous studies. Here, we describe an environmental case of resident Chromobacterium vaccinii in biofilms associated with Carex spp. roots in Moscow region, Russia (warm-summer humid continental climate zone). We performed broad characterization of individual properties as well as surrounding context for better understanding of the premise of $C$. vaccinii survival during the winter season. Genome properties of isolated strains propose some insights into adaptation to habit and biofilm mode of life, including social cheaters carrying $\Delta l u x R$ mutation. Isolated C. vaccinii differs from previously described strains in some biochemical properties and some basic characteristics like fatty acid composition as well as unique genome features. Despite potential to modulate membrane fluidity and presence of several genes responsible for cold shock response, isolated C. vaccinii did not survive during exposure to $4{ }^{\circ} \mathrm{C}$, while in the complex biofilm sample, it was safely preserved for at least half a year in vitro at $4{ }^{\circ} \mathrm{C}$. The surrounding bacterial community within the same biofilm with $C$. vaccinii represented a series of psychrophilic bacterial species, which may share resistance to low temperatures with other species within biofilm and provide $C$. vaccinii an opportunity to survive during the cold winter season.
\end{abstract}

Keywords: Chromobacterium vaccinii; biofilm; sharing goods; social cheater; bog microbiome; bacterial genome; violacein; cold adaptation; IDBac; QS mutant

\section{Introduction}

Biofilms and microbial mats are an important part of any ecosystem and one of the main biotic factors with a dramatic impact in metabolic processes and influence on other organisms' 
habits and species diversity (plants, insects, protozoans, and others). Bacterial species composition of biofilms both orchestrates and reflects variation in the ecological context, including pollution, climate change, other direct and indirect anthropogenic influences, as well as metabolic capacity and bioremediation processes. Despite awareness about the importance of bacterial abundance and biogeography, the worldwide distribution of bacterial species and their adaptation to different ecological niches remains poorly explored [1,2]. While clinical cases of different bacterial species isolation and description are broadly appreciated in clinical microbiology, environmental cases in microbial ecology and biogeography are limited. Reports of environmental Chromobacterium species isolation in Europe are rare: one in Poland (Chromobacterium violaceum from Ixodes ricinus ticks) and evidence of C. vaccinii isolation from bog in Tver region, Russia [3,4]. Moreover, numerous clinical cases of infections in Europe due to Chromobacterium species were discussed in a prism of global warming, but primary sources of infection and natural reservoirs of pathogenic Chromobacterium species remain undiscovered [5]. While members of the Chromobacterium genus are still considered as tropical/subtropical bacteria with poor viability at low temperatures, this is still questionable if changing environment and other processes affect the worldwide distribution of "tropical" Chromobacterium species or an abundance of these species are underestimated in the temperate climate zone. Even though some species of the genus were isolated from complex communities like rhizosphere and root-associated biofilms, most of these evidences were associated with an aquatic environment and some species were found in water samples [6-11]. Freezing water and ice coverage of water reservoirs during the winter seasons in temperate and cold climate zones might provide significant stress to Chromobacterium species.

Members of the Chromobacterium genus are known as producers of violacein, deoxyviolacein, cyanide, extracellular chitinase, and some other active compounds. These metabolites might have high environmental significance due to a broad range of biological activities, including antibacterial activity against both the planktonic and biofilm form of Gram-positive bacteria, insecticidal, antiprotozoal, possible antiviral, and fungicidal features [11-16]. Moreover, production of at least one of them, violacein, is higher in the biofilm mode of life and upregulated by intra- and interspecies quorum-sensing (QS) signals, which raises a question about the existence within multispecies biofilms in natural ecosystems [17,18]. A broad spectrum of activities provides competition advantages for Chromobacterium species and might promote niche partitioning in their presence, but little is known about the life of Chromobacterium species in non-optimal habits like climate zones with cold seasons.

Here, we describe the case of $C$. vaccinii isolation from quaking bog rhizospheres' biofilms in the European part of Russia, provide characteristics of isolates and surrounding bacterial community, and describe a naturally occurring QS mutant proposed as an example of social exploitation of community goods and representing evolutionary pressure on social cheating within biofilm [19].

\section{Materials and Methods}

The overall workflow of the current study is presented in Figure 1.

Samples collection and processing. Sediment samples, root-associated biofilms of sedge (Carex spp.), sphagnum moss, and water samples were collected in triplicates. For sediment samples, we scooped sediments directly into sampling plastic tubes $(\mathrm{V}=15 \mathrm{~mL})$. Water samples were collected into sampling plastic tubes $(\mathrm{V}=15 \mathrm{~mL}$ ) for microbiological examination and in 3-L glass bottles for water quality analysis. Sphagnum moss fragments were directly placed into sampling plastic tubes $(\mathrm{V}=50 \mathrm{~mL})$. For root-associated biofilms, we unearthed Carex spp. plants at the border of water and sphagnum moss, scraped rizodermis with root-associated biofilms using sterile scalpels, and then returned the plant to its initial place. All samples were immediately transferred to the laboratory at $+4{ }^{\circ} \mathrm{C}$. For dissociation of microbial aggregate, we vortexed samples at high speed for $5 \mathrm{~min}$ and then 10 -fold diluted samples processed with conventional microbiology plating on the following solid mediums: LB, TSA, M9 salts with $1 \%$ tryptone, nutrient agar, $\mathrm{BHI}$, and blood agar. Plates were incubated at $25^{\circ} \mathrm{C}$ for $48 \mathrm{~h}$. 


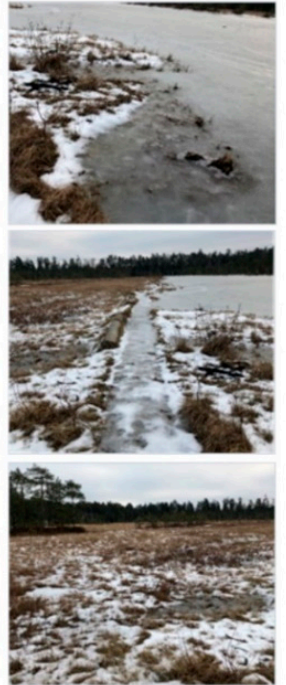

(a)

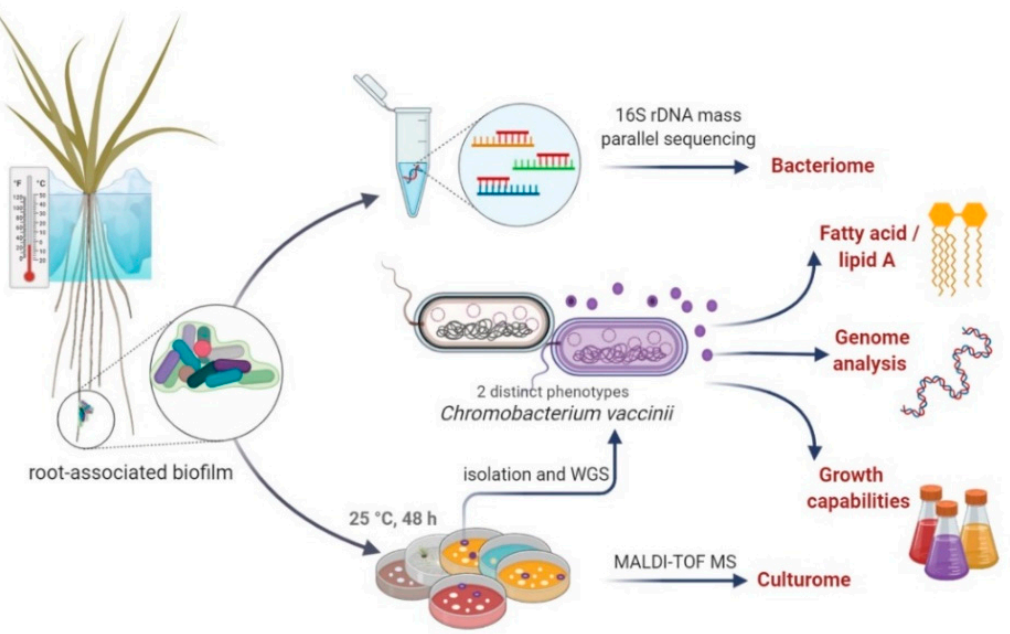

(b)

Figure 1. General description of the study design. (a) Photography of the location at the day of sampling. (b) Sample processing workflow. Picture was created with BioRender.com.

Water quality analysis was performed in MSULab company (Moscow, Russia).

Species identification and metabolic association network. MALDI-TOF MS identification: we picked single colonies from solid medium and processed with MALDI-TOF MS Sample Preparation and Data Acquisition. For MALDI-TOF MS analysis, proteins were extracted by using an extended direct transfer method that included a formic acid overlay as described in [20,21]. In brief, bacterial colonies were applied as a thin film onto a MALDI ground-steel target plate (Bruker Daltonics, Billerica, MA, USA). Over each bacterial smear, $1 \mu \mathrm{L}$ of $70 \%$ Optima $^{\mathrm{TM}} \mathrm{LC} / \mathrm{MS}$ Grade formic acid (Fisher Chemical, Hampton, NH, USA) was added and allowed to evaporate, followed by the addition and subsequent evaporation of $1 \mu \mathrm{L}$ of $10 \mathrm{mg} / \mathrm{mL} \alpha$-cyano-4-hydroxycinnamic acid solubilized in $50 \%$ acetonitrile, $2.5 \%$ trifluoroacetic acid, and 47.5\% water. All solvents were HPLC or MS grade.

Measurements were performed using an UltrafleXtreme mass-spectrometer (Bruker Daltonics, Billerica, MA, USA) equipped with a smartbeam ${ }^{\mathrm{TM}}-\mathrm{II}$ laser $(355 \mathrm{~nm})$. Natural product spectra were recorded in positive reflectron mode (2000 shots; RepRate: $2000 \mathrm{~Hz}$; delay: 8198 ns; ion source 1 voltage: $20 \mathrm{kV}$; ion source 2 voltage: $18.8 \mathrm{kV}$; lens voltage: $7.5 \mathrm{kV}$; mass range: 50 to $5000 \mathrm{Da}$, matrix suppression cutoff: $50 \mathrm{Da}$ ). Protein spectra were recorded in positive linear mode (1200 shots; RepRate: 1000; delay: 29,793 ns; ion source 1 voltage: $19.5 \mathrm{kV}$; ion source 2 voltage: $18.2 \mathrm{kV}$; lens voltage: $7.5 \mathrm{kV}$; mass range: $1.9 \mathrm{kDa}$ to $22 \mathrm{kDa}$ matrix suppression cutoff: $1.5 \mathrm{kDa})$. Protein spectra were corrected with an external Bruker Daltonics bacterial test standard (BTS). Natural products spectra were corrected with an external Bruker Daltonics peptide calibration standard and CHCA [2M + H]+ (379.0930 Da). Automated data acquisitions were performed using flexControl software v. 3.4.135.0 (Bruker Daltonics, Billerica, MA, USA) and flexAnalysis software v. 3.4. Spectra were automatically evaluated during acquisition to determine whether a spectrum was of high enough quality to retain and add to the sum of the sample acquisition.

For species identification, we used both a conventional database from Biotyper ${ }^{\circledR}$ (Bruker Daltonics, Billerica, MA, USA) and a recently introduced automatic IDBac algorithm [22]. Identification was validated in a selective manner through Sanger sequencing of $16 S$ rDNA amplicons obtained with 27F/1294R primers.

Sanger sequencing. $16 S$ rDNA amplicons obtained with 27F/1294R primers were sequenced according to the protocol of the BigDyeTerminator 3.1 Cycle Sequencing kit for the Genetic Analyzer 
3500 Applied Biosystems (Waltham, MA, USA). The electrophoretic DNA separation was performed in 50-cm capillaries with POP7 polymer.

$16 S$ rDNA bacteriome analysis. Total DNA was isolated from $1 \mathrm{~mL}$ of root-associated biofilm using a ZymoBIOMICS DNA Kit (Zymo Research, Irvine, CA, USA). Fragments of 16SrDNA gene containing V1-V4 hypervariable regions (max $753 \mathrm{bp}$ ) were amplified and used for preparation of paired-end libraries according to the KAPA HyperPlus (Roche, Basel, Switzerland) protocol. Libraries were checked with High Sensitivity DNA Chips on a 2100 Bioanalyzer System (Agilent, Santa Clara, CA, USA) and sequenced on NextSeq 500 (Illumina, San Diego, CA, USA) with NextSeq 500/550 High-Output Kit v2.5 (300 cycles). NGS data are available in GenBank: Bio Project PRJNA635774.

Two approaches were used for the data analysis. (1) The Microbial Genomics Module of CLC Genomic Workbench v.20.0.4 (QIAGEN, Germantown, MD, USA) was used with default settings to perform Operational Taxonomic Unit clustering. Greengenes database v.13_8 (Second Genome, Brisbane, CA, USA) was used as reference with a 97\% threshold. (2) SPAdes v.3.13.0 (St. Petersburg genome assembler, Russia, URL: http://cab.spbu.ru/software/spades/) was used for assembling the contigs, which were identified by BLAST NCBI with the rRNA/ITS databases [23]. Coverage of contigs of the same taxonomic units was summarized and served as an indicator of the taxon abundance. Diagram was created by Microsoft Excel (Microsoft, Redmond, WA, USA).

Phylogenetic analysis for the Proteobacteria fragments of $16 \mathrm{~S}$ ribosomal RNA gene was performed in MEGA 6.0 [24]. The evolutionary history was inferred by using the neighbor-joining method [25]. The distances for phylogeny reconstruction were computed using the Kimura 2-parameter [26], and are in the units of the number of base substitutions per site. The rate variation among sites was modeled with a gamma distribution (shape parameter $=0.25$ ). The analysis involved 70 nucleotide sequences. All ambiguous positions were removed for each sequence pair. There were a total of 1654 positions in the final dataset. Bootstrap analyses were performed with 1000 replicates [27].

Whole genome sequencing and annotation. DNA from bacterial cells of pigmented GIMC1602:ChrSima_v (ChrSV) and unpigmented GIMC1601:ChrSima_w (ChrSW) strains was isolated by a Wizard Genomic DNA purification kit (Promega, Madison, WI, USA). The KAPA HyperPlus (Roche, Basel, Switzerland) protocol was used for the libraries' preparation. Sequencing was performed on NextSeq 500 (Illumina, San Diego, CA, USA) with NextSeq 500/550 High-Output Kit v2.5 (300 cycles). CLC Genomic Workbench v.20.0.4 and SPAdes v.3.13.0 were used for genome assembling. CGView Server (http: //stothard.afns.ualberta.ca/cgview_server/) was applied for the visualization of assembling results and for the genome comparison [28]. The software Rapid Annotations Subsystems Technology (RAST) and SEED were used for genome annotation [29,30]. The conserved domains of the proteins were searched complementarily by the services KEGG (http://www.genome.jp/kegg), KEGGOC (http://www.genome.jp/tools/oc), and COGs (http://www.ncbi.nlm.nih.gov/COG). Prophage sequences were revealed with the help of PHASTER (PHAge Search Tool Enhanced Release, https://phaster.ca/) [31].

WGS data are available in GenBank: Bio Project PRJNA597450. Accession Numbers of the chromosome and plasmid are CP060046 and CP060045 for GIMC1602:ChrSima_v, CP060044, and CP060043 for GIMC1601:ChrSima_w.

Whole-genome-based taxonomic analysis was made by the Type (Strain) Genome Server (TYGS), a free bioinformatics platform of DSMZ, which is available under https://tygs.dsmz.de [32].

Biosynthetic gene clusters were predicted by antiSMASH v.5.1.2 available under https://antismash. secondarymetabolites.org/ [33]. This resource allows the rapid genome-wide identification, annotation, and analysis of secondary metabolite biosynthesis gene clusters in bacterial and fungal genomes.

Biochemical and growth properties characterization. Biochemical properties of $C$. vaccinii isolates were characterized using NEFERMtest 24 (Erba Lachema, Brno, Czechia) and ENDOtest (Erba Lachema, Brno, Czechia). For assessment of oxidase production, we used Microbact Oxidase Strips (Oxoid, Cheshire, England) and applied a traditional protocol using colonies that were 18-24 h old. Due to bacterial pigment interferences with color development, we used two additional methods: (a) early bacterial culture (before visible pigment production-approximately $12-16 \mathrm{~h}$ old); (b) an additional 
method useful for pigmented bacterial culture: a piece of filter paper was soaked one side in bacterial culture then placed on a test strip soaked side up and removed after 3 min of exposure; this let us to remove pigmented bacteria from the strip to avoid misinterpretation of the results. For validation of this approach, we used several strains of Pseudomonas aeruginosa as a positive sample.

For evaluation of the $\mathrm{pH}$ effects on the growing properties, TSB medium was adjusted to $\mathrm{pH}$ in a range from 3.0 to 9.0 with step 1.0 and then inoculated with C. vaccinii. For evaluation of the salinity effect, TSB medium w/o NaCl was supplemented with $\mathrm{NaCl}$ to $0-10 \%$ with step $0.5 \%$ and then inoculated with $C$. vaccinii. We accessed growing properties through the optical density of bacterial cultures at $600 \mathrm{~nm}$ after $48 \mathrm{~h}$ of incubation.

For assessment of the viability under different temperatures, we divided the stationary phase bacterial culture into 1-mL parts and incubated at $25^{\circ} \mathrm{C}, 4{ }^{\circ} \mathrm{C}$, and on ice. After desired periods of incubation, serial dilutions of bacterial culture were plated on TSA and incubated at $25^{\circ} \mathrm{C}$ for $48 \mathrm{~h}$ for CFU counting.

Mixed colony biofilm was prepared by mixing of equal amounts of overnight cultures, and $10 \mathrm{mkl}$ of bacterial mixture was spotted on TSB. Plates were incubated at $25^{\circ} \mathrm{C}$ for $48 \mathrm{~h}$.

For analysis of membrane fluidity adaptation to different temperatures, we grew $\mathrm{C}$. vaccinii on TSA at $25{ }^{\circ} \mathrm{C}$ during $24 \mathrm{~h}$, then changed the cultivation temperature for the next $48 \mathrm{~h}$, and finally proceeded to fatty acid analysis.

Fatty acid composition and lipid A structure analysis. Fatty acid methyl esters (FAMEs) were prepared as described previously with some modification [34]. Briefly, bacterial pellets were resuspended in solution for saponification $\left(300 \mathrm{mkl}\right.$ ) and incubated at $100^{\circ} \mathrm{C}$ for $30 \mathrm{~min}$. After incubation, $\mathrm{HCl}-\mathrm{MeOH}$ solution $(600 \mathrm{mkl})$ was added and heated at $80^{\circ} \mathrm{C}$ for $10 \mathrm{~min}$. Then, FAMEs were extracted by $10 \mathrm{~min}$ of mixing with $600 \mathrm{mkl}$ Hexane-MTBE $(600 \mathrm{mkl})$. The top phase was transferred into a new vial and used for analysis through GC-MS.

GC-MS analyses were carried out using Agilent 7820A (Agilent technologies, Santa Clara, CA, USA) gas chromatograph with a Maestro MS detector (Interlab, Moscow oblast, Russia) with $30 \mathrm{~m} \times 0.25 \mathrm{~mm}$ i.d. capillary column Rxi-5ms (Restek, Bellefonte, PA, USA). The injection volume was $1 \mu \mathrm{L}$, with a split ratio of 10:1 splitting gas-carrier. Injector and interface temperatures were 250 and $280^{\circ} \mathrm{C}$, respectively. The temperature program for the column started at $125^{\circ} \mathrm{C}$ for $0.5 \mathrm{~min}$, and then rose to 280 at $5{ }^{\circ} \mathrm{C} / \mathrm{min}$, and then to $320^{\circ} \mathrm{C}$ at $20^{\circ} \mathrm{C} / \mathrm{min}$; the end temperature was held for $2 \mathrm{~min}$. Electron impact (EI) spectra were obtained under $70 \mathrm{eV}$ ionization voltage and $150{ }^{\circ} \mathrm{C}$ source temperature. Registration of spectra was performed through a full scan at $40-550$ Th mass range.

Post-run analysis was performed with the following software: Agilent Mass Hunter Unknown Analysis (Agilent Technologies, Santa Clara, CA, USA), Enhanced Data Analysis (Agilent Technologies, Santa Clara, CA, USA), NIST MS Search 2.2 (NIST, Gaithersburg, MD, USA), and Microsoft Excel (Microsoft, Redmond, WA, USA). Equivalent chain-lengths of methyl ester derivatives of fatty acids were calculated as described [35].

Electron microscopy. For the electron microscopy, bacterial colonies were scraped off from plates, washed with sterile water three times, and fixed in 10\% neutral formalin. Electron microscopy was carried out with negative staining with 1\% uranyl acetate with JEM-2100 $200 \mathrm{kV}$ analytical electron microscope (JEOL, Tokyo, Japan).

\section{Results}

\subsection{Quaking Bog Description}

Quaking bog Volkovskoye with an abandoned quarry Sima developed over a lake approximately

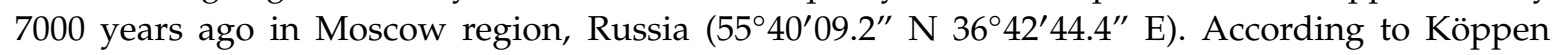
climate classification, this is a Dfb (warm-summer humid continental) climate zone. Quarry Sima was used for the exploitation of peat in 1800-1900s [36]. Nowadays, Volkovskoye is a relatively small bog-approximately 90,000 square meters in total with an open-water region less than 10,000 square 
meters (maximum depth $1.5 \mathrm{~m}$ ), surrounded by fir-tree forest. The major genus of higher plants on the edge are sphagnum moss and open water Carex spp. The bog is outlined by a stretch of birches and pines. A floating mat of sphagnum moss has a thickness of around $40 \mathrm{~cm}$. Analysis of the water chemical properties and composition confirms a low salt concentration, which is a common characteristic for quaking bogs (Table 1).

Table 1. Water quality analysis.

\begin{tabular}{|c|c|c|c|c|c|c|c|c|c|c|c|}
\hline \multicolumn{3}{|c|}{ General Characteristics } & \multicolumn{3}{|c|}{ Cations } & \multicolumn{3}{|c|}{ Anions } & \multicolumn{3}{|c|}{ Heavy Metals } \\
\hline Turbidity & 2.37 & OD530nm & $\mathrm{Mg}^{2+}$ & 0.26 & $\mathrm{mg} / \mathrm{L}$ & [SO4]- & 1.21 & $\mathrm{mg} / \mathrm{L}$ & $\mathrm{Hg}$ & $<0.00001$ & $\mathrm{mg} / \mathrm{L}$ \\
\hline Chromaticity & 36.9 & 0 & $\mathrm{Ca}^{2+}$ & 0.66 & $\mathrm{mg} / \mathrm{L}$ & {$[\mathrm{Cl}]-$} & 1.14 & $\mathrm{mg} / \mathrm{L}$ & V & $<0.0001$ & $\mathrm{mg} / \mathrm{L}$ \\
\hline Odour & 0 & grade $0-5$ & $\mathrm{Fe}^{2+}$ & 0.154 & $\mathrm{mg} / \mathrm{L}$ & [NO]- & 0.419 & $\mathrm{mg} / \mathrm{L}$ & Ba & 0.003 & $\mathrm{mg} / \mathrm{L}$ \\
\hline $\mathrm{pH}$ & 5.68 & pH units & $\mathrm{K}^{+}$ & 0.43 & $\mathrm{mg} / \mathrm{L}$ & [HCO3]- & $<6.1$ & $\mathrm{mg} / \mathrm{L}$ & Be & $<0.0001$ & $\mathrm{mg} / \mathrm{L}$ \\
\hline Hardness & $<0.060$ & $\mathrm{mg}-\mathrm{CaCO} 3 / \mathrm{L}$ & $\mathrm{Na}^{+}$ & 0.66 & $\mathrm{mg} / \mathrm{L}$ & [CO3]2- & $<6.0$ & $\mathrm{mg} / \mathrm{L}$ & B & $<0.05$ & $\mathrm{mg} / \mathrm{L}$ \\
\hline Chemical oxygen demand & 22.2 & $\mathrm{mg} / \mathrm{L}$ & $\mathrm{Al}^{+}$ & 0.051 & $\mathrm{mg} / \mathrm{L}$ & [NO2]- & $<0.1$ & $\mathrm{mg} / \mathrm{L}$ & Mo & $<0.0001$ & $\mathrm{mg} / \mathrm{L}$ \\
\hline $\mathrm{H} 2 \mathrm{~S}$ & $<0.002$ & $\mathrm{mg} / \mathrm{L}$ & {$\left[\mathrm{NH}_{4}\right]^{+}$} & 0.38 & $\mathrm{mg} / \mathrm{L}$ & [Br]- & $<0.05$ & $\mathrm{mg} / \mathrm{L}$ & Co & $<0.0001$ & $\mathrm{mg} / \mathrm{L}$ \\
\hline Petroleum products & 0.048 & $\mathrm{mg} / \mathrm{L}$ & $\mathrm{Li}^{+}$ & $<0.001$ & $\mathrm{mg} / \mathrm{L}$ & [PO3]- & $<0.1$ & $\mathrm{mg} / \mathrm{L}$ & $\mathrm{Ag}$ & $<0.0001$ & $\mathrm{mg} / \mathrm{L}$ \\
\hline Free alkalinity & $<0.1$ & $\mathrm{mM} / \mathrm{L}$ & & & & [F]- & 0.159 & $\mathrm{mg} / \mathrm{L}$ & $\mathrm{Zn}$ & 0.01 & $\mathrm{mg} / \mathrm{L}$ \\
\hline Total alkalinity & $<0.1$ & $\mathrm{mM} / \mathrm{L}$ & & & & & & & $\mathrm{Ni}$ & $<0.0001$ & $\mathrm{mg} / \mathrm{L}$ \\
\hline Sulfide minerals & $<0.002$ & $\mathrm{mg} / \mathrm{L}$ & & & & & & & $\mathrm{Si}$ & 0.556 & $\mathrm{mg} / \mathrm{L}$ \\
\hline Dry weight & 7.37 & $\mathrm{mg} / \mathrm{L}$ & & & & & & & $\mathrm{Cr}$ & $<0.0001$ & $\mathrm{mg} / \mathrm{L}$ \\
\hline Conductivity & 11 & $\mathrm{mkS} / \mathrm{sm}$ & & & & & & & $\mathrm{Sr}$ & 0.003 & $\mathrm{mg} / \mathrm{L}$ \\
\hline & & & & & & & & & $\mathrm{Cd}$ & $<0.0001$ & $\mathrm{mg} / \mathrm{L}$ \\
\hline & & & & & & & & & As & $<0.0001$ & $\mathrm{mg} / \mathrm{L}$ \\
\hline & & & & & & & & & $\mathrm{Cu}$ & 0.002 & $\mathrm{mg} / \mathrm{L}$ \\
\hline & & & & & & & & & $\mathrm{Pb}$ & $<0.0001$ & $\mathrm{mg} / \mathrm{L}$ \\
\hline
\end{tabular}

\subsection{Individual Properties of Chromobacterium vaccinii}

\subsubsection{Isolation and Species-Level Identification}

C. vaccinii was found during investigation of biofilms composition in the quaking bog Volkovskoye. Biofilm samples were collected in triplicates in winter (in January 2020; average daytime temperature $-7{ }^{\circ} \mathrm{C}\left(20^{\circ} \mathrm{F}\right)$, night $\left.-13^{\circ} \mathrm{C}\left(9^{\circ} \mathrm{F}\right)\right)$ when the bog was covered with ice and the water temperature was 2-4 ${ }^{\circ} \mathrm{C}$. While, previously, we had already found Chromobacterium spp. at the same bog during the summer season (August, 2019), the isolates did not survive neither at temperatures of $4-8{ }^{\circ} \mathrm{C}$ during short (few days) storage on plates with solid mediums (BHI, TSA, LB) nor during deep freezing in storage medium supplemented with glycerol (data not shown). This was the premise to collect samples during the cold season and exclude the possibility of a transient occurrence of "tropical" bacterial species carried by reservoir birds or insects during migration.

After collection and transportation of sediment samples, root-associated biofilms of Carex spp., sphagnum moss, and water sample bacteria were grown on the following solid mediums: LB, TSA, M9 salts with 1\% tryptone, nutrient agar, BHI, and blood agar. After incubation in aerobic conditions, $25{ }^{\circ} \mathrm{C}$ for $48 \mathrm{~h}$, we isolated 18 circular, smooth, and raised colonies with entire margins and deep violet pigmentation from all root-associated biofilms of Carex spp. but neither from water samples nor from sphagnum moss. A single CFU with the same properties was detected in one sediment sample. Identification of isolated colonies by MALDI Biotyper ${ }^{\mathrm{TM}}$ (Bruker, Billerica, MA, USA) resulted in probable genus identification with a score no more than 1.71 for Chromobacterium spp. At the time of identification, the number of specters in the database related to the Chromobacterium genus was restricted, with only two species: C. violaceum and C. substugae. Additionally, three unpigmented colonies of Chromobacterium spp. were found in root-associated biofilms of Carex spp.

To confirm they belonged to the Chromobacterium genus, we performed $16 S$ rDNA sequencing for all isolates. Identification based on $16 S$ rDNA sequence analysis resulted in more than $99 \%$ similarity to $C$. violaceum, C. vaccinii, and C. piscinae species. Due to the high homology between these Chromobacterium species, $16 S$ rDNA sequence analysis was not enough for secure species identification. So, we performed WGS (whole-genome sequencing) for one pigmented and one unpigmented isolate assigned as isolates GIMC1602:ChrSima_v (ChrSV) and GIMC1601:ChrSima_w (ChrSW), respectively. Assembled WGS data were used for determination of the closest type strain genome 
with the help of TYGS [32]. The TYGS database includes type strains of the eight Chromobacterium species: C. amazonense DSM 26508, C. haemolyticum DSM 19808, C. phragmitis IIBBL 112-1, C. phragmitis IIBBL 112-1, C. pseudoviolaceum LMG 3953, C. sphagni IIBBL 14B-1, C. subtsugae PRAA4-1, C. vaccinii MWU205, and C. violaceum ATCC 12472. The digital DNA-DNA hybridization (dDDH) value was the highest for the pairs ChrSV-C. vaccinii MWU205 and ChrSW-C. vaccinii MWU205: $87.5 \%$ and $87.4 \%$, respectively, with confidence intervals (C.I.s) of $84.0-90.3 \%$ and $83.9-90.2 \%$ (Supplementary Figure S1). The type C. vaccinii strain MWU205 was initially isolated from cultivated cranberry bogs in Cape Code, Massachusetts [6,7].

\subsubsection{General Phenotype Characterization}

In order to obtain a broad description of phenotype, we performed electron microscopy imaging, biochemical characterization, growth properties, and analysis of fatty acids contents, including the lipid A structure of LPS.

Negative staining electron microscopy of pigmented and unpigmented isolates showed bacillus with a single polar flagellum for both pigmented and unpigmented isolates (Figure 2).
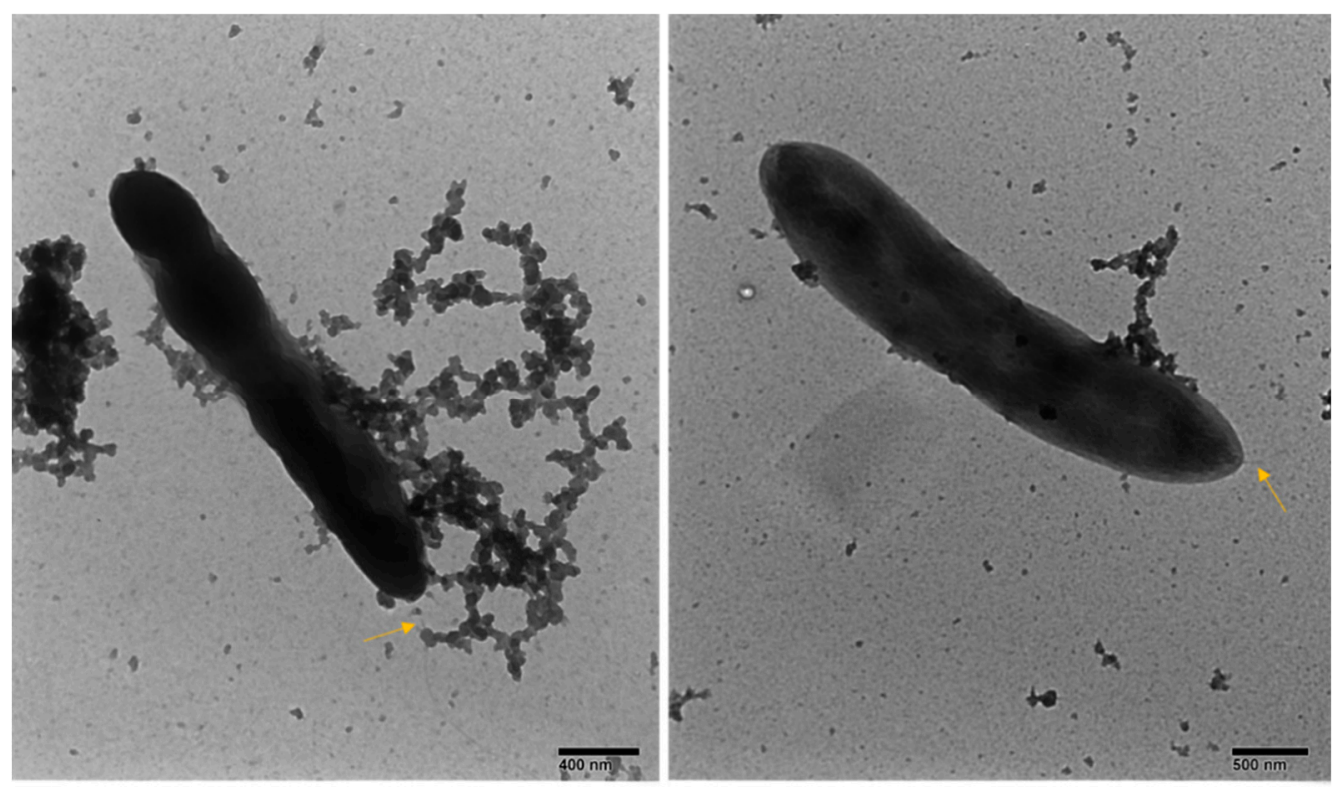

Figure 2. Negative staining electron microphotographs of isolated C. vaccinii-pigmented strain (left) and unpigmented strain (right). The arrow shows the flagellum of bacteria.

Biochemical characterization of isolates was different from previously described features (Table 2). Fermentation tests of all isolates were positive for gamma-glutamyltransferase, arginine dehydrolase, phosphatase, and fermentation of trehalose. Not all but most isolates were positive for N-Acetyl-beta-D-Glucosaminidase and Simmon's citrate test. Some other infrequent biochemical features among isolates included utilization of ornithine, lysine, mannitol, xylose, arabinose, galactose, and sucrose. Isolates were able to grow in a broad a range of $\mathrm{pH}$ and salinity.

The most significant and valuable difference in terms of the general species description was negative oxidase reaction for all isolates. We confirmed the negative results of the oxidase test with two different approaches: using early bacterial culture (before development of pigmentation) and using the modified pigmented strain method, unpigmented isolates were also tested with both methods. Negative oxidase reaction is not common for members of Neisseriacea, but for a minor part of Chromobacterium, isolates were previously mentioned [37,38]. 
Table 2. Biochemical properties of $C$. vaccinii isolated strains.

\begin{tabular}{|c|c|}
\hline Characteristic & Fermentation or Number of $+/-$ Isolates if Variable \\
\hline oxidase & - \\
\hline indole production & - \\
\hline bGL & - \\
\hline NAG & $16 / 18$ \\
\hline $\mathrm{SCI}$ & $16 / 18$ \\
\hline LAC & - \\
\hline MAN & $1 / 18$ \\
\hline TRE & + \\
\hline XYL & $5 / 18$ \\
\hline ARA & $3 / 18$ \\
\hline aGA & - \\
\hline bGA & - \\
\hline MAL & - \\
\hline GAL & $1 / 18$ \\
\hline MLT & - \\
\hline CEL & - \\
\hline SUC & $2 / 18$ \\
\hline INO & - \\
\hline GGT & + \\
\hline PHS & + \\
\hline ESL & - \\
\hline $\mathrm{H} 2 \mathrm{~S}$ & - \\
\hline MAL & - \\
\hline ONP & - \\
\hline SAL & - \\
\hline SOR & - \\
\hline MLB & - \\
\hline GLP & - \\
\hline DUL & - \\
\hline ADO & - \\
\hline ART & - \\
\hline RAF & - \\
\hline$b X Y$ & - \\
\hline $\mathrm{NaCl}, \%$ range & $0-3$ \\
\hline $\mathrm{pH}$ range & $4.0-8.0$ \\
\hline pigmentation & $3 / 18$ \\
\hline
\end{tabular}

$+=$ all tested isolates were positive; $-=$ all tested isolates were negative; numbers represent positive isolates from total number of tested isolates.

Considering the possible causes of a negative oxidase test, our genomic studies revealed that the Chromobacterium isolates have a versatile aerobic respiratory system, including aa3 (locus tags ChrSV_0681 -0691), cbb3 (ChrSV_4418-4423) cytochrome c oxidases, and quinol oxidases: one copy of cytochrome O ubiquinol oxidase cyo (ChrSV_1078-1082) and two copies of cytochrome d ubiquinol oxidase cyd (ChrSV_1410 -1411 and ChrSV_3076-3077). The respiratory system comprises also the complexes of enzymes responsible for NADH and succinate oxidation (ChrSV_4656-4669 and ChrSV_4524-4536). On the other hand, Chromobacterium is famous for cyanide production, which is a diagnostic test of Chromobacterium during growth on complex medium [39]. The hcn $A B C$ gene cluster encoding hydrogen cyanide synthase was revealed in the genomes of the pigmented and unpigmented strains (ChrSV_3735-3737).

The oxidase test is used to identify bacteria that produce cytochrome c oxidase. However, this enzyme is cyanide sensitive, so both aa 3 and cbb3 cytochrome c oxidases could be inhibited by cyanide production. The survival of Chromobacterium under these conditions is provided by other enzymes of the respiratory system: NADH and succinate oxidation is highly resistant to inhibition by cyanide [40]. Additionally, the ubiquinol oxidases may enhance tolerance to oxidative and nitrosative stress in some bacterial species [41].

We performed conventional fatty acid methyl ester (FAME) characterization of our isolates as the key features of microbial species characterization. The FAME profile for our type isolate ChrSV in 
comparison with other characterized species is presented in Table 3 and FAMEs for different isolates in this study are presented in Supplementary Table S1.

Table 3. Fatty acid compositions of Chromobacterium species.

\begin{tabular}{|c|c|c|c|c|c|c|c|c|c|c|c|c|c|c|}
\hline & 1 & 2 & 3 & 4 & 5 & 6 & 7 & 8 & 9 & 10 & 11 & 12 & 13 & 14 \\
\hline 11:0 & - & - & 0.2 & - & - & - & - & - & - & 0.2 & - & - & - & - \\
\hline $10: 03 \mathrm{OH}$ & 1.8 & 3.2 & 3.4 & 4.3 & 4.7 & 2.9 & 3.7 & 1.5 & 3.2 & 4.6 & 3 & 2.2 & 5.1 & 2.4 \\
\hline $12: 0$ & 2.4 & 3.8 & 3.8 & 5.0 & 3.9 & 4.0 & 4.2 & 9.7 & 3.3 & 8.8 & 3.2 & 3.1 & 4.9 & 3.3 \\
\hline $11: 03 \mathrm{OH}$ & - & - & - & - & - & - & - & - & - & - & - & - & 0.4 & - \\
\hline $13: 0$ & - & - & - & - & - & - & - & - & - & - & - & - & 0.4 & - \\
\hline $12: 02 \mathrm{OH}$ & 1.8 & 1.9 & 2.0 & 2.9 & 2.4 & 1.4 & 2.3 & - & 1.9 & 0.2 & 1.9 & 1.6 & 3.3 & 1.7 \\
\hline $12: 03 \mathrm{OH}$ & 2.8 & 3.3 & 3.4 & 4.0 & 3.6 & 2.5 & 2.9 & 1.4 & 2.9 & 4.4 & 2.8 & 2.5 & 4.8 & 2.6 \\
\hline $13: 02 \mathrm{OH}$ & - & - & - & - & - & - & - & 0.4 & - & - & - & - & - & - \\
\hline $14: 1 \mathrm{w} 7 \mathrm{c}$ & 0.4 & - & - & - & - & - & - & - & - & - & - & - & - & - \\
\hline $14: 1 \mathrm{w} 5 \mathrm{c}$ & 0.1 & 0.2 & 0.2 & 0 & 0.4 & - & 0.3 & 0.4 & - & - & 0 & 0.2 & - & - \\
\hline $14: 0$ & 2.2 & 2.3 & 2.1 & 3.2 & 2.5 & 2.3 & 3.3 & 4.0 & 2 & 2.6 & 3.1 & 2.5 & 3.5 & 2.0 \\
\hline $15: 0$ iso & - & - & - & - & - & - & - & 0.5 & - & - & - & - & - & - \\
\hline $15: 0$ iso $G$ & - & - & - & - & - & - & - & 0.7 & - & - & - & - & - & - \\
\hline $15: 1 \mathrm{w} 8 \mathrm{c}$ & 0.1 & - & - & - & - & - & - & - & - & - & - & - & - & - \\
\hline $15: 1$ w6c & 0.2 & - & - & - & - & - & - & - & - & - & - & - & - & - \\
\hline $15: 0$ & 1.0 & - & - & 1.3 & - & - & 0.9 & & 1 & 0.6 & 2.3 & - & 3.0 & - \\
\hline $16: 1 \mathrm{w} 7 \mathrm{c}$ & 43.7 & 42.7 & 41.9 & 41.9 & 47.1 & 42.5 & 34.1 & 38.6 & 38.9 & 33.4 & 28.7 & 38.5 & 27.5 & 36.3 \\
\hline $16: 1 w 5 c$ & 0.4 & 0.3 & 0.3 & 0.3 & 0.5 & - & - & - & - & 0.3 & 0 & 0.2 & - & - \\
\hline $16: 0$ & 28.4 & 28.4 & 29.6 & 25.0 & 24.0 & 27.3 & 26.1 & 29.7 & 30.2 & 25.8 & 32 & 31.5 & 26.6 & 28.5 \\
\hline $17: 1$ w6c & - & - & - & 0.2 & - & - & 0 & - & 0.2 & - & - & & 0.4 & - \\
\hline 17:0 CYCLO & 0.2 & 0.4 & - & - & 0.4 & - & 2.9 & - & - & - & 13.2 & 0.2 & 4.3 & 1.3 \\
\hline $18: 2 \mathrm{w} 6,9 \mathrm{c}$ & - & - & - & - & - & - & 4.2 & - & - & - & - & - & - & - \\
\hline $18: 1 \mathrm{w} 9 \mathrm{c}$ & - & - & - & - & - & - & 2 & - & - & - & - & - & - & - \\
\hline $18: 1 \mathrm{w} 7 \mathrm{c} / 12 \mathrm{t} / 9 \mathrm{t}$ & 12.5 & 13.1 & 12.6 & 10.6 & 10.3 & 12.0 & 12.3 & 5.5 & 15.7 & 18.8 & 8.7 & 15.9 & 14.8 & 19.3 \\
\hline 18:0 & 1.8 & 0.4 & 0.5 & - & 0.2 & 0.6 & 0.4 & 1.6 & 0.5 & 0 & 0.6 & 0.5 & 0.3 & 0.4 \\
\hline SFA/MUFA * & 0.6 & 0.6 & 0.7 & 0.7 & 0.5 & 0.6 & 0.7 & 1.0 & 0.7 & 0.7 & 1.1 & 0.7 & 0.8 & 0.6 \\
\hline Hydroxy FA ** & 6.4 & 8.4 & 8.8 & 11.2 & 10.7 & 6.8 & 8.6 & 3.3 & 8 & 9.2 & 7.7 & 6.3 & 13.6 & 6.7 \\
\hline
\end{tabular}

1, GIMC1602:ChrSima_v strain in this study; 2, MWU300-C. vaccinii [7]; 3, MWU205-C. vaccinii [7]; 4, PRAA4-1

-C. subtsugae [42]; 5, IIBBL 14B-1 C. sphagni [6]; 6, CCUG 53,230 C. haemolyticum [43]; 7, ATCC 12,472 C. violaceum [42];

8, LAM1188 C. rhizoryzae [8]; 9, DSM 170,043-C. subtsugae [42]; 10, CC-SEYA-1-C. aquaticum [44]; 11, LMG 3947

-C. piscinae [45]; 12, IIBBL 112-1 C. phragmitis [46];13, LMG 3953 C. pseudoviolaceum [45]; 14, CBMAI310T C. amazonense [47].

* saturated FA/monounsaturated FA; ** summed hydroxy fatty acids.

According to the FAME analysis, the predominant fatty acids (FAs) were $\mathrm{C} 16: 1 \omega 7 \mathrm{c}(43.7 \%), \mathrm{C} 16: 0$ $(28.4 \%)$, and C18: $1 \omega 7 \mathrm{c}(12.5 \%)$. The fatty acids profile of GIMC 1602 was different from any previously reported data. The close resemblance was found in the C16 fatty acids between GIMC1602:ChrSima_v, C. vaccinii (MWU 300, MWU 205), C. subtsugae PRAA4-1, C. sphagni IIBBL 14B-1, and C. haemolyticum CCUG 53230. Some differences were found in the hydroxy fatty acids content and other minor fatty acids. Namely, GIMC1602:ChrSima_v has a low level of hydroxy fatty acid and contains 14:1 and 15:1 FA in contrast to other C. vaccinii strains (MWU 300, MWU 205). To determine if hydroxy fatty acid belongs to LPS or not, we analyzed the lipid A structure. Lipid A contained all three hydroxy fatty acids (Supplementary Figure S2) and its structure was the same as described for C. violaceum NCTC $9694[48,49]$. 


\subsubsection{Genome Characterization and Comparison with Known Strains of C. vaccinii.}

Genome analysis of the pigmented (ChrSV) and unpigmented (ChrSW) C. vaccinii strains demonstrated that both genomes consist of chromosome $(5,278,675$ and 5,273,834 bp, respectively) and plasmid (45,365 bp). Alignment of ChrSV and ChrSW chromosomes with the help of the BLAST NCBI with Genome Data Base revealed the highest homology (99.27\% identity and 90\% coverage) with C. vaccinii strain 21-1 genome, Accession Number CP017707.1. This strain was isolated from bog in Beltsville, Maryland, USA, a place with a humid subtropical climate. The chromosome of $C$. vaccinii strain 21-1 is less than the chromosome of ChrSV by 237,445 bp.

The ChrSV/ChrSW genomes have the biggest number of prophages-12 and 7 of them are intact. The genome of $C$. vaccinii strain $21-1$ has only 6 prophages (4 intact), 5 of which are similar to prophages of the ChrSV/ChrSW genomes. The second C. vaccinii complete genome, the genome of strain XC0014 (Accession Number CP022344.1), is even smaller, and has six prophages (five intact), but only two of them are similar to prophages of the ChrSV/ChrSW genomes. It should be noted that if the first two strains were isolated from the bogs, the C. vaccinii XC0014 strain had another source of isolation: the soil in Zhejiang Province of China. However, the climate in Zhejiang is humid subtropical as in Beltsville, in contrast to the climate in the Moscow region.

The next difference between the ChrSV/ChrSW genomes and genomes of 21-1 and XC0014 is the presence of the plasmid (45,365 bp). In the Microbial Genome Data Base of NCBI, only 3 Chromobacterium genomes from 58 genomes with different levels of assembly have plasmids: C. violaceum FDAARGOS_635 (CP050991.1, 42,965 bp), Chromobacterium sp. IIBBL 112-1 (NZ_CP029496.1, 17,589 bp), and Chromobacterium. sp. IIBBL 274-1 (NZ_CP029555.1, 74,363 bp). The plasmid of the type strain of C. violaceum ATCC 12,472 was submitted in GenBank separately (MG651603.1., 44,212 bp) [50].

The ChrSV/ChrSW plasmids did not have similarity with the Chromobacterium sp. plasmids but were homologous to plasmids of both C. violaceum strains with a coverage of 83\%: FDAARGOS_635-93.05\% identity, ATCC 12,472-92.51\%. Note that C. violaceum strains were isolated from different sources: FDAARGOS_635 is a clinical isolate (University of Louisville, US), and ATCC 12,472 is a freshwater isolate (Malaya, Malaysia).

So, the ChrSV/ChrSW genomes are the biggest from known C. vaccinii genomes and differ in the presence of a considerable number of prophages (including intact prophages) and plasmid homologous to the plasmids of $C$. violaceum strains.

\subsection{Regulatory Nature of Unpigmented Isolate}

We isolated three unpigmented strains of $C$. vaccinii and performed whole-genome sequencing for one of them: ChrSW. We identified the full vioABCDE operon in the genome sequence of unpigmented isolate, which gave us a reason to hypothesize on the regulatory nature of absence pigmentation in the ChrSW isolate. Regulation of violacein production depends on quorum-sensing (QS) signals [51]. Closer investigation of the genome region responsible for the LuxI/LuxR regulatory QS pathway revealed deletion of a large DNA fragment including the $l u x R$ sequence, which made classical positive-feedback regulation of the LuxI/LuxR system in response to AHL impossible (Figure 3).

Lack of luxR expression due to deletion in the genome of the ChrSW strain resulted in insensitivity to external AHL and inability to increase the expression of endogenous AHL synthase LuxI, so all underlying modulation of gene expression remains intact, including expression of the vioABCDE operon (Figure 4A). A clear pattern of unpigmented cells in a mixed (equal mix of pigmented and unpigmented isolates) colony biofilm model confirmed the inability of the $\Delta l u x R$ mutant to respond through the AHL-LuxI/LuxR pathway (Figure 4B). 

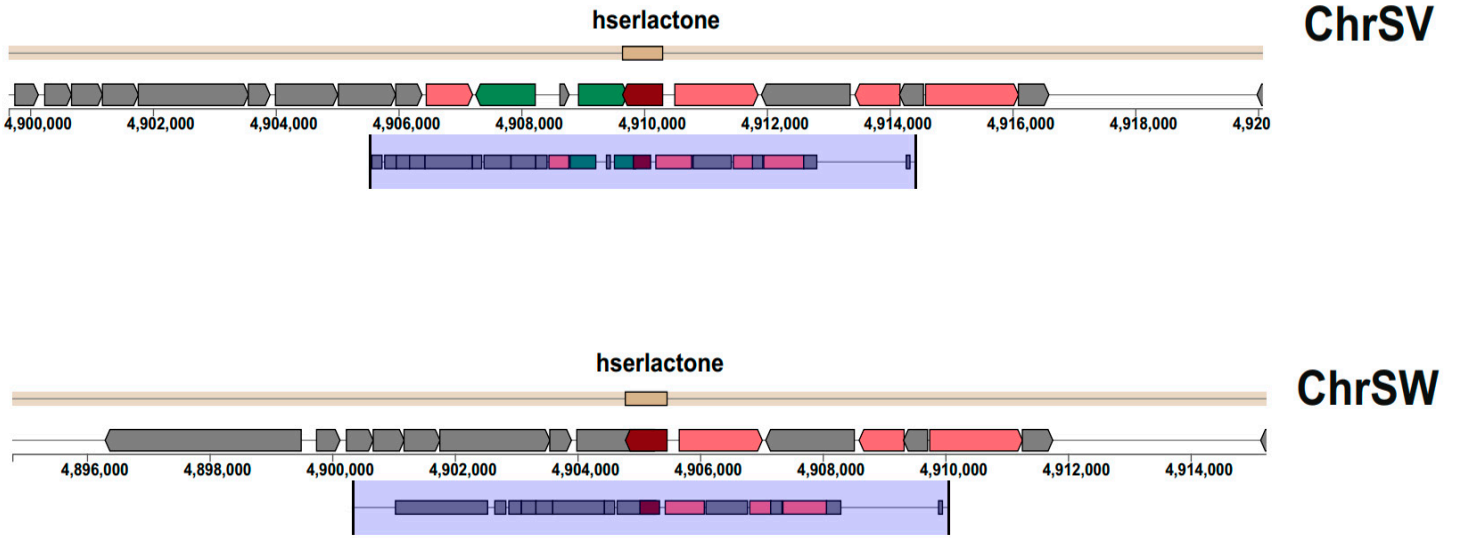

Legend:

$\square$ core biosynthetic genes $\square$ additional biosynthetic genes $\square$ transport-related genes $\square$ regulatory genes $\square$ other genes $\square$ resistance

Figure 3. Biosynthetic gene cluster for homoserine lactone in natural pigmented (ChrSV) and unpigmented (ChrSW) isolate of C. vaccinii. The resource antiSMASH v.5.1.2 was used for prediction.

A

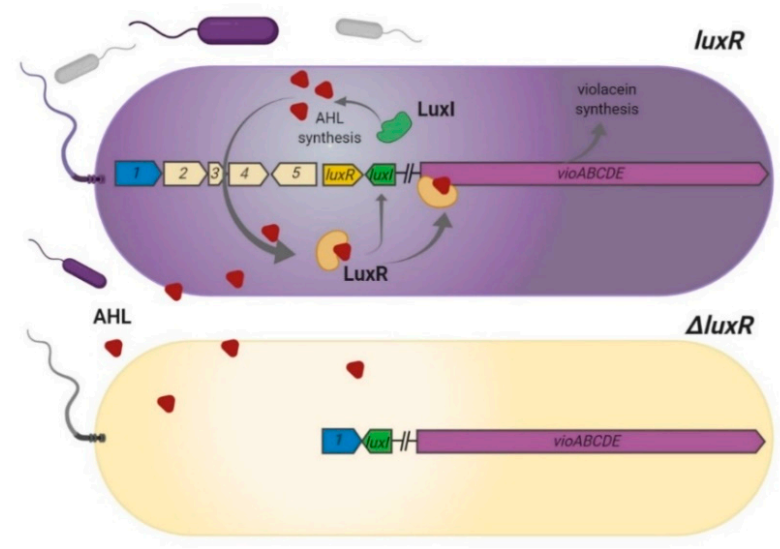

B

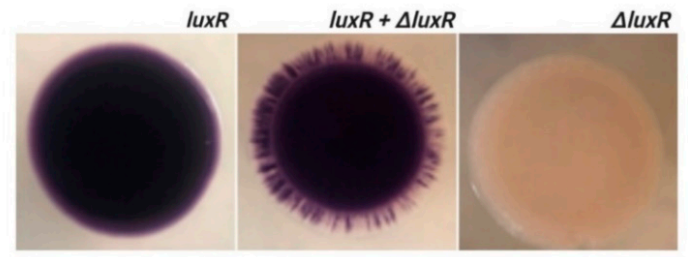

Figure 4. Nature of the unpigmented strain. (A) Mechanism of luxI/luxR regulation of violacein production and inability to develop pigmentation in natural $\Delta l u x R$ isolate. LuxR binds with exogenous AHL and activates LuxI production; LuxI syntheses endogenous AHL; increasing AHL concentration amplify AHL-QS signaling loop; increasing concentration of LuxR-AHL complex activates the vioABCDE operon and bacteria produce violacein. In case of the $\triangle l u x R$ strain, AHL signaling is interrupted and vioABCDE is not active. Unpigmented natural isolate of $C$. vaccinii has deletion of luxR and 1-5 protein-coding genes. (B) Inability of natural $\triangle l u x R$ isolate to produce violacein in a mixed biofilm colony model. Biofilm colonies formed by pigmented strain (luxR); mix of pigmented and unpigmented strains $(l u x R+\Delta l u x R)$; unpigmented strain $(\Delta l u x R)$. Mixed biofilm colony has clear patterns of pigmented and unpigmented zones, which indicates the inability of $\Delta l u x R$ strain to respond and amplify AHL-QS signal and produce violacein in a mixed bacterial population. Picture was created with BioRender.com. 
It is interesting to note that clear patterns at the edge of mixed colony biofilm indicated zip-like meso-scale structures (Supplementary Figure S3). The appearance of these structures was similar to recently observed intra-colony channels in E. coli [52].

\subsection{Adaptability to Low Temperatures}

Even though C. vaccinii was isolated during the cold season, loss of viability was described during C. violaceum exposure to low temperatures [53]. During storage of plates (TSA, LB, and blood agar) with isolated C. vaccinii at $4{ }^{\circ} \mathrm{C}$, we observed complete loss of bacterial culture recovery from a single colony after several days (within 1 week), while recovery during storage at $25^{\circ} \mathrm{C}$ was restricted by drying of solid medium (4 weeks). In the genome of isolated C. vaccinii, we revealed some genes responsible for temperature adaptation: $\mathrm{ABC}$ transporters for the putrescine import, genes for spermidine synthesis and export, the gene of cold shock protein, and the operon for trehalose transport. To investigate the ability to survive at low temperatures in liquid LB medium, we incubated stationary phase cultures of ChrSV at 4 or at $25^{\circ} \mathrm{C}$ for different periods of time. After at least $4 \mathrm{~h}$ of incubation at $4{ }^{\circ} \mathrm{C}$, we observed a two-fold decrease in viability in comparison with $25^{\circ} \mathrm{C}$ incubation; by 1 week of incubation, this viability difference was more than 20 times lower and by the fourth week of incubation, we observed complete loss of viability for the sample in the $4{ }^{\circ} \mathrm{C}$ storage condition (Figure 5a). At the same time, recovery of $C$. vaccinii from initial root-associated biofilm samples placed in the same LB medium was possible at least after 6 months of storage at $4{ }^{\circ} \mathrm{C}$ (due to numerous numbers of $\mathrm{C}$. vaccinii colonies, we evaluated recovery in a qualitative manner).
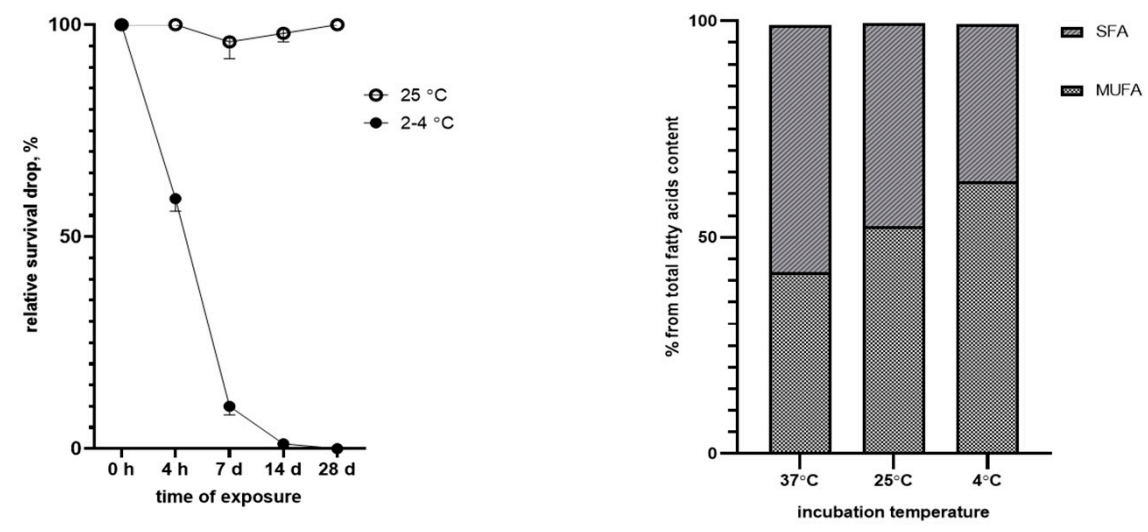

\begin{tabular}{|l|c|c|c|c|}
\hline $\begin{array}{l}\text { Recovery from } \\
\text { initial biofilm } \\
\text { sample during } \\
\text { storage at 2-4 }\end{array}{ }^{\circ} \mathrm{C}$ & + & + & + & + \\
\cline { 2 - 5 } & & $+4 \mathrm{~d}$ & $\mathbf{2 8 ~ d}$ & $180 \mathrm{~d}$ \\
\hline
\end{tabular}

(a)

(b)

Figure 5. Influence of low temperatures on C. vaccinii. (a) Survival under exposure of liquid culture of C. vaccinii to sub-zero $\left(2-4{ }^{\circ} \mathrm{C}\right.$ ) temperatures presented in $\% \%$ relative exposure to $25^{\circ} \mathrm{C}$ (presented as $100 \%$ ) and recovery from the initial biofilm sample during storage at $2-4{ }^{\circ} \mathrm{C}$. (b) Membrane fluidity adaptation through changing saturation of fatty acids during exposure to different temperatures.

Changing membrane fluidity through balancing saturated/unsaturated fatty acid content is an important part of bacterial cold adaptation [54]. To explore the ability to change SFA/MUFA content during exposure to different temperatures, we performed FAME analysis for bacterial culture grown up at $25^{\circ} \mathrm{C}$ and then shifted to 4 or $37^{\circ} \mathrm{C}$ for $48 \mathrm{~h}$. After $48 \mathrm{~h}$ of exposure to $4{ }^{\circ} \mathrm{C}$, we observed a significant shift to monounsaturated fatty acids (MUFAs) and the opposite in the case of $37^{\circ} \mathrm{C}$ exposure (Figure 5b). So, isolated C. vaccinii has at least one mechanism of low-temperature stress reaction: changing membrane fluidity, but this attempt did not prevent loss of viability in monoculture, while the 
multi-species environmental biofilm sample provided an opportunity to survive for at least half a year at $4{ }^{\circ} \mathrm{C}$ in vitro.

\subsection{Surrounding Bacterial Community}

\subsubsection{Culturome Analysis}

Bacteria grown on the solid mediums from the root-associated biofilms of Carex spp. were defined as culturome. Conventional Biotyper ${ }^{\circledR}$ identification of culturable bacteria was significantly restricted due to the low number of environmental species in the database, so we used the IDBac approach to build a phylogenetic grouping based on MALDI-TOF MS small molecule data using the algorithm described by Laura M. Sanchez and Brian T. Murphy [22,55]. Cooperation in terms of support during growing requires crossing of metabolic pathways between different species. While it is difficult to predict cross-species metabolic interaction in natural multispecies communities, the IDBac approach estimated the small metabolites fingerprint [55]. For the general understanding of possible C. vaccinii metabolism crossing with other bacterial species, we created a metabolic-associated network (MAN) with all culturable bacteria within the same biofilm (Figure 6).

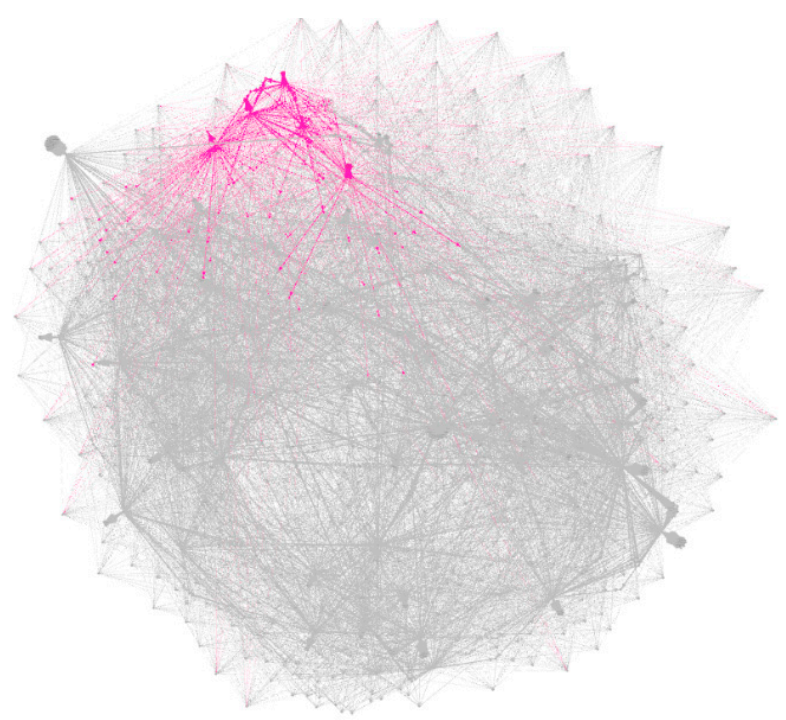

Figure 6. Metabolic-associated network (MAN) of all culturable bacteria from the same with Chromobacterium biofilms. Small molecule metabolites from C. vaccinii are colored in pink, metabolites from other species are colored in grey. Cumulative distance was built via modularity analysis with default thresholds in Gephi after matrix and media signals were subtracted automatically from the network in IDBac.

The metabolic-associated network demonstrated clear clustering of $C$. vaccinii within culturable bacteria and showed compounds with unique mass (at least 20 masses were not found in any other bacteria within culturome); probably, there were specialized metabolites by $C$. vaccinii. At the same time, a lot of crossing with other species was observed as a sign of integration into the bacterial community. A mass list of the small molecule metabolites is available in Supplementary Table S2.

For evaluation of the IDBac approach in bacterial identification, we performed $16 S \mathrm{rDNA}$ sequencing for selected isolates from different groups and confirmed their correct classification at least on a group level. This gave us a general understanding of prevalent bacterial groups in culturome. In root-associated biofilms of Carex spp., we found that members of Pseudomonadaceae accounted for more than $80 \%$ of the culturable bacterial species (Figure $7 a$ ). 


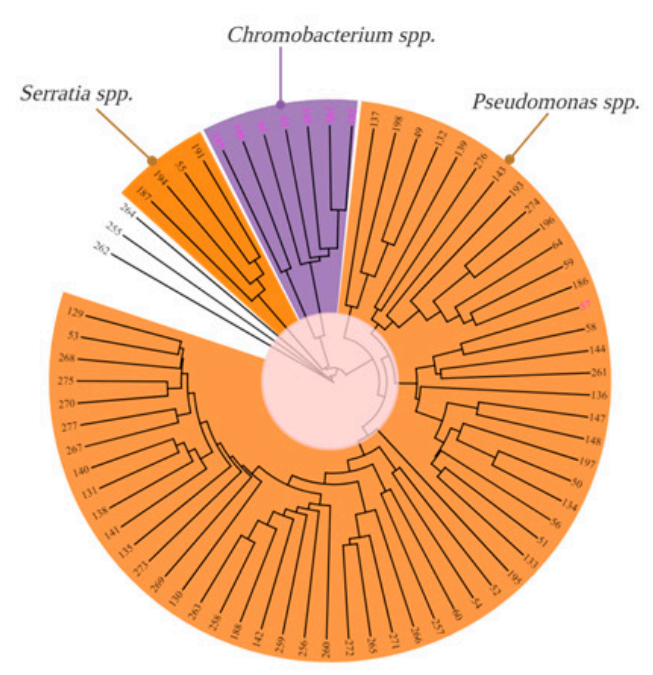

(a)

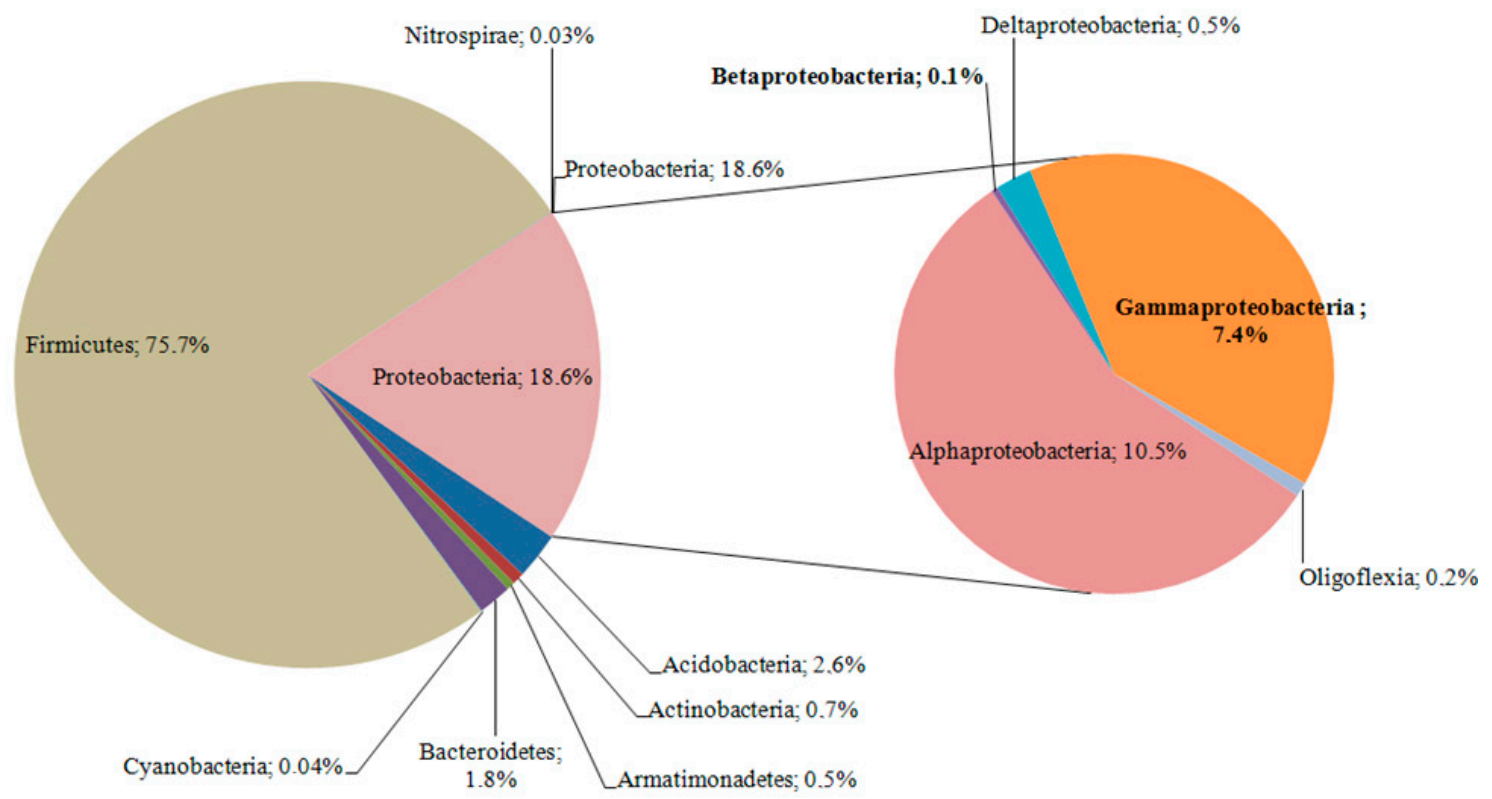

(b)

Figure 7. Surrounding bacterial community in biofilm. (a) Culturome of root-associated biofilm obtained through IDBac fingerprint grouping. Numbers represent the colony identification number on plates. Mixed species colonies excluded from analysis; (b) Proportion of different bacterial taxonomic groups in $16 S \mathrm{rDNA}$ microbiome of the root-associated biofilm. Inset in the diagram reveals the phylum of Proteobacteria. 


\subsubsection{Microbiome Analysis}

For description of the whole microbial community within the root-associated biofilm, we performed massive parallel sequencing of $16 S \mathrm{rDNA}$ amplicons. Microbiome was presented by the eight phyla: Acidobacteria, Actinobacteria, Armatimonadetes, Bacteroidetes, Cyanobacteria, Firmicutes, Nitrospirae, and Proteobacteria (Figure $7 b$ ). The most abundant were Firmicutes $(75.7 \%)$, followed by Proteobacteria (18.6\%). Firmicutes included the five genera, among which Clostridia predominated (99.9\%). Clostridia revealed in the root-associated microbiome were phylogenetically most closely related to a psychrophilic species Clostridium estertheticum and other species of the cluster I clostridia isolated from an Antarctic microbial mat [56]. Proteobacteria were presented by the 5 classes, including 73 genera (Figure 8).

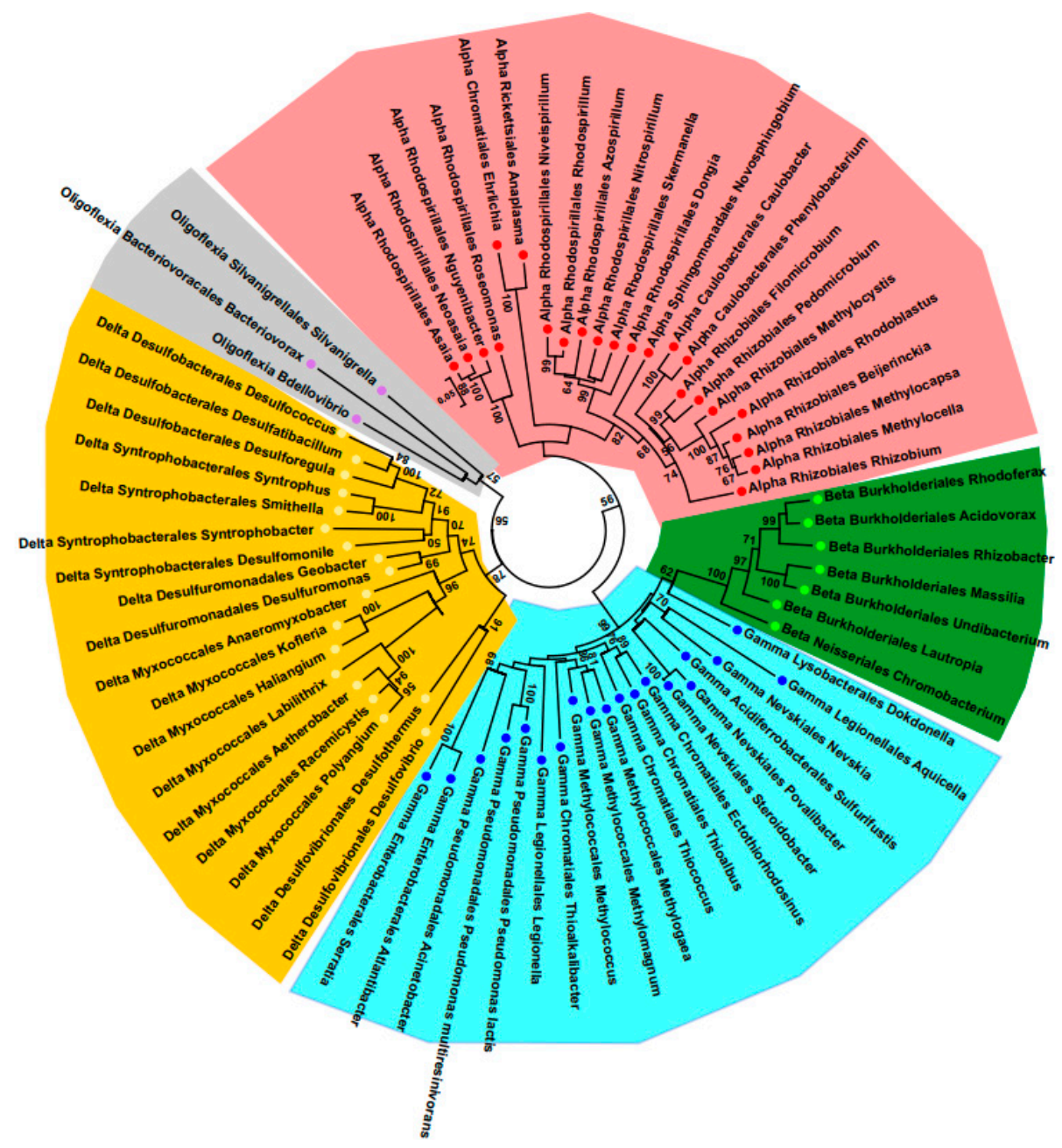

Figure 8. Taxonomic diversity of Proteobacteria in the microbiome of the root-associated biofilm. Red circles-Alphaproteobacteria, blue circles-Gammaproteobacteria, yellow circles-Deltaproteobacteria, green circles-Betaproteobacteria, purple circles-Oligoflexia.

The most abundant were Alfa- and Gammaproteobacteria, but the taxonomic diversity of Deltaproteobacteria was as great as Gammaproteobacteria. Pseudomonas predominated in Gammaproteobacteria (64\%), which was partly consistent with the data of the culturome. However, Serratia was revealed only in a trace amount, the same as Chromobacterium. It should be noted that in the microbiome, few abundant Betaproteobacteria were represented mainly by the order Burkholderiales and only one genus of Neisseriales was detected. The amount of Serratia and Chromobacterium revealed in the microbiome is in contrast to the fact that these genera did appear in culturome. 
The abundance of the phylum Acidobacteria (2.6\%) was an order of magnitude lower than Firmicutes and Proteobacteria but agreed with the data of Pankratov et al. on the quantification by FISH of acidobacteria in native peat sampled from sphagnum-dominated wetlands of different geographic locations (0.1-4.1\%) [57]. The phylum Bacteroidetes was even less abundant $(1.8 \%)$. Additionally, as demonstrated by Li et al., the presence of Bacteroides in the root-associated biofilm may depend on the type of the plant: Bacteroides were detected in samples of narrow-leaved cattail roots but were absent in common reed root samples [58].

Analyzing 20 of the most abundant genera, we found they belong to the next phyla: 1 -Firmicutes, 10- Proteobacteria, 2-Bacteroidetes, 5-Acidobacteria, 1-Actinobacteria, and 1-Armatimonadetes. Thus, the microbial community of the root-associated biofilm demonstrated amazing diversity even in the cold winter season.

\section{Discussion}

Chromobacterium species demonstrate significant biological activity against other microbes and insects in laboratory settings, but little is known about the overall context of their natural habits and their environmental adaptation. They are widely distributed in tropical and subtropical zones and still believed to be tropical bacterial species. Investigation of environmental cases of Chromobacterium species isolation in the temperate climate zone and analysis of their adaptation potential, surrounding microbiome, and description of their natural niche may shed light on the system biology of complex environmental communities and microbial biogeography at a time of discussion around global warming.

We described a case of a resident $C$. vaccinii in root-associated biofilm in a quaking bog in the Dfb climate zone. Nowadays, there are numerous cases of environmental Chromobacterium isolation in Europe and one of them is also related to bog, which is in line with the first reported case of $C$. vaccinii isolation from cranberry bogs in Cape Code, USA [3,7]. Additionally, the ability to grow in vitro in low salinity and the water composition from the site of sample collection support the existence of $C$. vaccinii in an oligotrophic environment. Biofilm formation in an environment with low levels of nutrients and significant climate variations around the year helps to create a sustainable surrounding due to the accumulation of nutrients in the biofilm matrix and create a network for metabolic cooperation to degrade xenobiotics and enhance resistance to threats [59].

In support of the unique biofilm mode of cooperation, we found a QS-deficient mutant among C. vaccinii isolates, which has a mutation in the key regulatory system LuxI/LuxR. The QS-deficient mutant had no visible pigmentation due to an inability to respond and amplify AHL signaling essential for vioABCDE operon induction. This observation is in line with recently published data: violacein biosynthesis depends on the LuxI/LuxR quorum sensing system and as was recently published, the $\Delta c v i R$ (homolog of luxR) mutant of $C$. violaceum lost visible pigmentation due to a dramatic drop in violacein production [48]. Absence of pigmentation is the most noticeable phenotype of $\Delta l u x R$, while it is well-known that an inability to respond through the LuxI/LuxR system leads to significant changes in other important processes and minimization of the cooperative traits. Interruption of QS-mediated regulation makes crosstalk with other bacteria complicated and might lead to minimization of production but not consumption of public goods [60]. Occurrence and persistence of quorum-sensing bacteria represent social cheaters within the biofilm and stress the general idea of public goods in the bacterial social community. It is important to note that in our study, the QS-deficient mutant was isolated from a natural complex biofilm so this is an additional point to support the laboratory-proved theory around social cheaters in biofilms. One of the costly social goods might be polysaccharides or other molecules for bacterial coating and providing protection from temperature perturbations. This could explain the viability of tropical Chromobacterium during the cold winter season.

While isolated C. vaccinii showed in vitro some adaptability to sub-zero temperatures through changes of the membrane fatty acid saturation, after long-term storage, recovery was dramatically better from complex initial biofilm samples rather than from pure bacterial suspension. Such cold resistance in a prism of the biofilm lifestyle might be related to the extracellular matrix composition, 
which serves as a social good [61]. This is consistent with the previous observations that environmental parameters rather than phylogeny determine the composition of biofilm matrix in microbial mats from extreme environments [62]. It might be proposed that the ability of Chromobacterium to survive in the bog during the cold winter season was due to sharing goods provided by a diverse microbial community of the root-associated biofilm of Carex spp.

Analysis of the surrounding bacterial community by $16 \mathrm{~S} r \mathrm{DNA}$ microbiome showed a prevalence of psychrophilic anaerobic Clostridium species, previously described as members of a microbial mat in an Antarctic freshwater lake [56]. The second prevalent bacterial belong to the Rhodoblastus genus, which is a freshwater bacteria and might be associated with sphagnum peat $[63,64]$. The vast majority of other bacteria are also known as psychrophilic or psychrotolerant. Besides the psychrophilic clostridia (Firmicutes) mentioned above, Acidobacteria are adapted to growth at low temperatures, as demonstrated Pankratov et al., who isolated the acidobacteria from nine Sphagnum-dominated wetlands of West Siberia and European North Russia [57]. Steroidobacter agariperforans (Gammaproteobacteria, Nevskiales) may be characterized as psychrophilic so far as ATCC recommended growing the type strain BAA2459 at $3{ }^{\circ} \mathrm{C}$ (https://www.lgcstandards-atcc.org/). Another representative of Nevskiales, Povalibacter, was revealed with a high abundance from natural and constructed wetlands, demonstrating stability in different geographic zones [65]. From the two genera of Bacteroides, Mucilaginibacter was characterized as psychrotolerant by Pankratov et al., who isolated this bacterium from the phagnum peat bog Bakchar, in the Tomsk region of western Siberia [66], and Flavobacterium was described as "cool to cold environments" by Van Trappe et al., who investigated bacteria from Antarctic lakes [67].

The four genera of Proteobacteria belong to methanotrophic bacteria, which could be characterized as psychrotrophs (facultative psychrophiles, or psychrotolerants) according to the data of Kevbrina et al., who demonstrated that some methanotrophic species could grow at $10^{\circ} \mathrm{C}$ [68]. Silvanigrella aquatica (Oligoflexia) can be recognized as psychrotrophs too on the basis of growth in culture in the temperature range of $10-32{ }^{\circ} \mathrm{C}$ and the habitat in the freshwater lake located in the Black Forest Mountains (Schwarzwald), Germany [69]. Pseudomonas, the third abundant genus in the biofilm community, is known to be cold tolerant due to a wide geographic distribution and ability to grow even at a high-altitude location in the northwestern Indian Himalayas [70].

However, in relation to some bacteria from the list of the most abundant in the root-associated biofilm, the same question arises as in relation to Chromobacterium: how can a bacterium that has a temperature optimum in a monoculture at $25-30{ }^{\circ} \mathrm{C}$ and quickly dies at $4{ }^{\circ} \mathrm{C}$ accumulate in large quantities at low temperatures? If Fimbriimonas (Armatimonadetes) is mesophilic with a growth temperature range of $15-30{ }^{\circ} \mathrm{C}$ [71], then Rhodoblastus (Alphaproteobacteria) was described as mesophilic with optimum growth at $25-30^{\circ} \mathrm{C}$, when cultivated in laboratory, but it has been isolated from the Sosvyatskoe ombrotrophic bog located in Tver Region with cold winter temperatures [72]. Moreover, the type strain IC-180T of the genus Aciditerrimonas has growth temperatures of $35-58{ }^{\circ} \mathrm{C}$ [73], but at the same time, Aciditerrimonas is known as the abundant genus of Actinobacteria in a worldwide range of samples from wetland soil and sediment according to the 16S rDNA microbiome analysis [74], and Oloo et al. revealed that sphagnum interstitial water samples were enriched in genera, such as Aciditerrimonas, on the base of $16 \mathrm{~S}$ rDNA sequencing data too [75].

The most intriguing was Ehrlichia, which is granulocytic ehrlichiosis agent of humans and other vertebrates, and a tick-borne pathogen. The abundance of Ehrlichia was comparable with the abundance of some Acidobacteria and methanotrophic bacteria in the microbial community of the root-associated biofilm. Since culturing Ehrlichia species requires a canine macrophage cell line or tick cell line, it is complicated by temperature $\left(34-37^{\circ} \mathrm{C}\right)$ and aerobic conditions for eukaryotic cell growth [76]. All identification of Ehrlichia in the environment is associated with ticks. As revealed by Zintl et al., tick density in marsh/bog sites was even slightly higher than in woodland sites [77]. The appearance of Ehrlichia in the Moscow region bog could be connected with the change in the distribution of ticks 
and with the fact that bog is a comfortable place for prolonged nonparasitic phases of ticks, requiring a microclimatic relative humidity of at least $80 \%$ to avoid fatal desiccation [78].

Such diverse and complex cultivating conditions of representatives of the root-associated biofilm members support the idea of cooperation within the microbial community to provide a survival opportunity for a broad range of requirements.

Disagreement between the IDBac approach and sequencing data was expected and might be partially explained by the unculturable state of some species and inappropriate culture conditions for growth, like the aerobic condition, inappropriate temperature, and medium composition. Meanwhile, we noted an unexpected prevalence of some species among colonies on solid medium despite their low abundance according to NGS data: Serratia accounted for less than $0.003 \%$ from all $16 S \mathrm{rDNA}$ bacteriome and was presented $>1500$ times lower than Pseudomonas spp. but still grew and was randomly picked for low-throughput IDBac analysis. The same is true for the Chromobacterium genus. A significant limitation in culturome data collection is not only well-known growth competition but also growth cooperation in favorable conditions for some species in closer proximity on the Petri dish in laboratory settings.

Thus, the combination of microbiological and genomic approaches provides a versatile understanding of the microbial community of the root-associated biofilm.

\section{Conclusions}

Altogether, we described the isolation of resident $C$. vaccinii from an environmental complex biofilm in a temperate climate zone, which is not common for members of the Chromobacterium genus. This $C$. vaccinii has several genotype and phenotype unique properties in comparison with all other members of the genus. Additionally, an unpigmented isolate with interrupted QS-mediated signaling was represented by social cheaters within the biofilm and might be a sign of adaptation to the community lifestyle through minimization of costly production of social goods, while survival during exposure to sub-zero temperatures (i.e., winter season) completely relies on the surrounding microbial community and factor serving as a sharing good produced by other biofilm members will be in focus for the future research.

Supplementary Materials: The following are available online at http:/www.mdpi.com/2076-2607/8/11/1696/s1, Figure S1: Tree inferred with FastME 2.1.6.1 from GBDP (Genome BLAST Distance Phylogeny) distances calculated from genome sequences. Figure S2: Lipid A structure analysis. Figure S3: Channel-like structures at the edge of the mixed colony biofilm. Table S1: Fatty acid composition of several Chromobacterium vaccinii isolates. Table S2: Mass list of small molecule metabolites of culturable bacterial species from root-associated biofilm.

Author Contributions: Conceptualization, D.A.E., O.L.V. and A.I.S.; methodology, M.S.K., N.N.R., E.I.A., V.S.R., A.I.S., K.V.D., N.B.P., D.A.G., N.V.S., A.A.S.; software, A.N.S., M.S.K.; validation, A.I.S., M.S.K., E.I.A., N.N.R.; investigation, M.S.K., N.N.R., E.I.A., O.L.V., V.S.R., A.I.S., A.A.S., K.V.D., D.A.G.; resources, I.V.D.; data curation, O.L.V., M.S.K.; writing — original draft preparation, review and editing D.A.E., O.L.V.; biofilm research consulting, Y.M.R.; project administration, D.A.E.; funding acquisition, A.L.G. All authors have read and agreed to the published version of the manuscript.

Funding: This research was funded by President Grant to DE, grant number MK-2241.2019.7, and by the Government Contract N 056-00078-19-00 for N.F. Gamaleya National Research Center.

Conflicts of Interest: The authors declare no conflict of interest.

\section{References}

1. Hutchins, D.; Jansson, J.; Remais, J.; Rich, V.; Singh, B.; Trivedi, P. Climate change microbiology—Problems and perspectives. Nat. Rev. Microbiol. 2019, 17, 391-396. [CrossRef] [PubMed]

2. Antwis, R.; Griffiths; Harrison, X.; Aranega-Bou, P.; Arce, A.; Bettridge, A.; Brailsford, F.; Menezes, A.; Devaynes, A.; Forbes, K.; et al. Fifty important research questions in microbial ecology. FEMS Microbiol. Ecol. 2017, 93, 93. [CrossRef] [PubMed] 
3. Dobrovolskaya, T.; Golovchenko, A.; Yurchenko, E.; Yakushev, A.; Manucharova, N.; Lysak, L.; Kostina, N. Bacterial Communities of Regressive Spots in Ombrotrophic Bogs: Structure and Functions. Microbiology 2020, 89, 107-114. [CrossRef]

4. Stojek, N.; Dutkiewicz, J. Studies on the occurrence of Gram-negative bacteria in ticks: Ixodes ricinus as a potential vector of Pasteurella. Ann. Agric. Environ. Med. 2004, 11, 319-322. [PubMed]

5. Jędruszczak, A.; Bąk, M.W.; Nosal, R.B.; Maciejewski, M.; Marczewski, K. Sepsis caused by Chromobacterium violaceum—Probably the first case in Europe, or Macbeth read anew. Ann. Agric. Environ. Med. 2019, 26, 508-510. [CrossRef] [PubMed]

6. Blackburn, R., Jr.; Sparks, M.; Kuhar, D.; Mitchell, A.; Gundersen-Rindal, D. Chromobacterium sphagni sp. nov., an insecticidal bacterium isolated from Sphagnum bogs. Int. J. Syst. Evol. Microbiol. 2017, 67, 3417-3422. [CrossRef] [PubMed]

7. Soby, S.; Gadagkar, S.; Contreras, C.; Caruso, F. Chromobacterium vaccinii sp. nov., isolated from native and cultivated cranberry (Vaccinium macrocarpon Ait.) bogs and irrigation ponds. Int. J. Syst. Evol. Microbiol. 2013, 63, 1840-1846. [CrossRef]

8. Zhou, S.; Guo, X.; Wang, H.; Kong, D.; Wang, Y.; Zhu, J.; Dong, W.; He, M.; Hu, G.; Zhao, B.; et al. Chromobacterium rhizoryzae sp. nov., isolated from rice roots. Int. J. Syst. Evol. Microbiol. 2016, 66, 3890-3896. [CrossRef]

9. Bolívar-Anillo, H.J.; Orozco-Sanchez, C.J.; Lima, G.S.; dos Santos, G.F. Endophytic Microorganisms Isolated of Plants Grown in Colombia: A Short Review. J. Microb. Biochem. Technol. 2016, 8, 1-5. [CrossRef]

10. Dall'Agnol, L.; Martins; Vallinoto, A.; Ribeiro, K. Diversity of Chromobacterium violaceum isolates from aquatic environments of state of Pará, Brazilian Amazon. Memórias Instituto Oswaldo Cruz 2008, 103, 678-682. [CrossRef]

11. Barreto, E.; Torres, A.; Barreto, M.; Vasconcelos, A.; Astolfi-Filho, S.; Hungria, M. Diversity in antifungal activity of strains of Chromobacterium violaceum from the Brazilian Amazon. J. Ind. Microbiol. Biotechnol. 2008, 35, 783-790. [CrossRef]

12. Dodou, H.; Batista, A.; Medeiros, S.; Sales, G.; Rodrigues, M.; Pereira, P.; Nogueira, P.; Silveira, E.; Grangeiro, T.; Nogueira, N. Violacein antimicrobial activity on Staphylococcus epidermidis biofilm. Nat. Prod. Res. 2019, 1-4. [CrossRef] [PubMed]

13. Andrighetti-Fröhner, C.; Antonio, R.; Creczynski-Pasa, T.; Barardi, C.; Simões, C. Cytotoxicity and potential antiviral evaluation of violacein produced by Chromobacterium violaceum. Memórias Instituto Oswaldo Cruz 2003, 98, 843-848. [CrossRef]

14. Bilsland, E.; Tavella, T.A.; Krogh, R.; Stokes, J.E.; Roberts, A.; Ajioka, J.; Spring, D.R.; Andricopulo, A.D.; Costa, F.T.; Oliver, S.G. Antiplasmodial and trypanocidal activity of violacein and deoxyviolacein produced from synthetic operons. BMC Biotechnol. 2018, 18, 22. [CrossRef]

15. Lozano, G.L.; Guan, C.; Cao, Y.; Borlee, B.R.; Broderick, N.A.; Stabb, E.V.; Handelsman, J. A chemical counterpunch: Chromobacterium violaceum ATCC31532 produces violacein in response to translation-inhibiting antibiotics. BioRxiv 2019, 589192. [CrossRef]

16. Kim, H.J.; Choi, H.S.; Yang, S.Y.; Kim, I.S.; Yamaguchi, T.; Sohng, J.K.; Park, S.K.; Kim, J.-C.; Lee, C.H.; Gardener, B.M.; et al. Both extracellular chitinase and a new cyclic lipopeptide, chromobactomycin, contribute to the biocontrol activity of Chromobacterium sp. C61. Mol. Plant Pathol. 2013, 15, 122-132. [CrossRef] [PubMed]

17. Mart'yanov, S.V.; Letarov, A.V.; Ivanov, P.A.; Plakunov, V.K. Stimulation of Violacein Biosynthesis in Chromobacterium violaceum Biofilms in the Presence of Dimethyl Sulfoxide. Microbiology 2018, 87, 437-440. [CrossRef]

18. McClean, K.; Winson, M.; Fish, L.; Taylor, A.; Chhabra, S.; Camara, M.; Daykin, M.; Lamb, J.; Swift, S.; Bycroft, B.; et al. Quorum sensing and Chromobacterium violaceum: Exploitation of violacein production and inhibition for the detection of N-acylhomoserine lactones. Microbiology 1997, 143, 3703-3711. [CrossRef] [PubMed]

19. Boyle, K.; Heilmann, S.; Ditmarsch, D.; Xavier, J. Exploiting social evolution in biofilms. Curr. Opin. Microbiol. 2013, 16, 207-212. [CrossRef]

20. Freiwald, A.; Sauer, S. Phylogenetic classification and identification of bacteria by mass spectrometry. Nat. Protoc. 2009, 4, 732-742. [CrossRef] 
21. Schumann, P.; Maier, T. Chapter 13 MALDI-TOF Mass Spectrometry Applied to Classification and Identification of Bacteria. Method Microbiol. 2014, 41, 275-306. [CrossRef]

22. Clark, C.M.; Costa, M.S.; Conley, E.; Li, E.; Sanchez, L.M.; Murphy, B.T. Using the Open-Source MALDI TOF-MS IDBac Pipeline for Analysis of Microbial Protein and Specialized Metabolite Data. J. Vis. Exp. 2019. [CrossRef] [PubMed]

23. Bankevich, A.; Nurk, S.; Antipov, D.; Gurevich, A.A.; Dvorkin, M.; Kulikov, A.S.; Lesin, V.M.; Nikolenko, S.I.; Pham, S.; Prjibelski, A.D.; et al. SPAdes: A New Genome Assembly Algorithm and Its Applications to Single-Cell Sequencing. J. Comput. Biol. 2012, 19, 455-477. [CrossRef] [PubMed]

24. Tamura, K.; Stecher, G.; Peterson, D.; Filipski, A.; Kumar, S. MEGA6: Molecular Evolutionary Genetics Analysis version 6.0. Mol. Biol. Evol. 2013, 30, 2725-2729. [CrossRef] [PubMed]

25. The neighbor-joining method: A new method for reconstructing phylogenetic trees. Mol. Biol. Evol. 1987. [CrossRef]

26. Kimura, M. A simple method for estimating evolutionary rates of base substitutions through comparative studies of nucleotide sequences. J. Mol. Evol. 1980, 16, 111-120. [CrossRef]

27. Felsenstein, J. Confidence limits on phylogenies: An approach using the bootstrap. Evol. Int. J. Org. Evol. 1985, 39, 783-791. [CrossRef]

28. Grant, J.R.; Stothard, P. The CGView Server: A comparative genomics tool for circular genomes. Nucleic Acids Res. 2008, 36, W181-W184. [CrossRef]

29. Aziz, R.K.; Bartels, D.; Best, A.A.; DeJongh, M.; Disz, T.; Edwards, R.A.; Formsma, K.; Gerdes, S.; Glass, E.M.; Kubal, M.; et al. The RAST Server: Rapid annotations using subsystems technology. BMC Genom. 2008, 9, 75. [CrossRef]

30. Overbeek, R.; Begley, T.; Butler, R.M.; Choudhuri, J.V.; Chuang, H.-Y.; Cohoon, M.; de Crécy-Lagard, V.; Diaz, N.; Disz, T.; Edwards, R.; et al. The Subsystems Approach to Genome Annotation and its Use in the Project to Annotate 1000 Genomes. Nucleic Acids Res. 2005, 33, 5691-5702. [CrossRef]

31. Arndt, D.; Grant, J.R.; Marcu, A.; Sajed, T.; Pon, A.; Liang, Y.; Wishart, D.S. PHASTER: A better, faster version of the PHAST phage search tool. Nucleic Acids Res. 2016, 44, W16-W21. [CrossRef] [PubMed]

32. Meier-Kolthoff, J.P.; Göker, M. TYGS is an automated high-throughput platform for state-of-the-art genome-based taxonomy. Nat. Commun. 2019, 10, 2182. [CrossRef] [PubMed]

33. Blin, K.; Shaw, S.; Steinke, K.; Villebro, R.; Ziemert, N.; Lee, S.Y.; Medema, M.H.; Weber, T. antiSMASH 5.0: Updates to the secondary metabolite genome mining pipeline. Nucleic Acids Res. 2019, 47, W81-W87. [CrossRef]

34. Sasser, M.; Kunitsky, C.; Jackoway, G.; Ezzell, J.; Teska, J.; Harper, B.; Parker, S.; Cheek, W.; Ezzell, J.; Hopkins, K.; et al. Identification of Bacillus anthracis from Culture Using Gas Chromatographic Analysis of Fatty Acid Methyl Esters. J. Aoac. Int. 2019, 88, 178-181. [CrossRef]

35. Christie, W. Equivalent chain-lengths of methyl ester derivatives of fatty acids on gas chromatography a reappraisal. J. Chromatogr. A 1988, 447, 305-314. [CrossRef]

36. Gavrilov, M.; Zhmyleva, A.; Shakhparonov, V.; Zakharchenko, D. Flora and Fauna of the Western Part of Moscow Region; Selected Student Research Works Conducted at Summer Field Practice at S. N. Skadovsky Zvenigorod Biological Station; KMK Scientific Press: Moscow, Russia, 2020; Volume 10, ISBN 978-5-907099-05-0.

37. Dhar, S. The oxidase activity of chromobacterium. J. Clin. Pathol. 1973, 26, 304. [CrossRef] [PubMed]

38. Sivendra, R.; Lo, H.S. Identification of Chromobacterium violaceum: Pigmented and non-pigmented strains. J. Gen. Microbiol. 1975, 90, 21-31. [CrossRef]

39. Sneath, P.H.A. Identification methods applied to Chromobacterium. In Identification Methods for Microbiologists; Gibbs, B.M., Skinner, F.A., Eds.; Academic Press: London, UK; New York, NY, USA, 1966; part A; pp. 15-20.

40. Niven, D.F.; Collins, P.A.; Knowles, C.J. The respiratory system of Chromobacterium violaceum grown under conditions of high and low cyanide evolution. J. Gen. Microbiol. 1975, 90, 271-285. [CrossRef]

41. Forte, E.; Borisov, V.; Vicente, J.; Giuffrè, A. Chapter Four Cytochrome bd and Gaseous Ligands in Bacterial Physiology. Adv. Microb. Physiol. 2017, 71, 171-234. [CrossRef]

42. Martin, P.; Gundersen-Rindal, D.; Blackburn, M.; Buyer, J. Chromobacterium subtsugae sp. nov., a betaproteobacterium toxic to Colorado potato beetle and other insect pests. Int. J. Syst. Evol. Microbiol. 2007, 57, 993-999. [CrossRef]

43. Han, X.; Han, F.; Segal, J. Chromobacterium haemolyticum sp. nov., a strongly haemolytic species. Int. J. Syst. Evol. Microbiol. 2008, 58, 1398-1403. [CrossRef] [PubMed] 
44. Young, C.; Arun, A.; Lai, W.; Chen, W.; Chou, J.; Chao, J.; Shen, F.; Rekha, P.; Kämpfer, P. Chromobacterium aquaticum sp. nov., isolated from spring water samples. Int. J. Syst. Evol. Microbiol. 2008, 58, 877-880. [CrossRef] [PubMed]

45. Kämpfer, P.; Busse, H.-J.; Scholz, H.C. Chromobacterium piscinae sp. nov. and Chromobacterium pseudoviolaceum sp. nov., from environmental samples. Int. J. Syst. Evol. Microbiol. 2009, 59, 2486-2490. [CrossRef] [PubMed]

46. Blackburn, M.B.; Farrar, R.R., Jr.; Sparks, M.E.; Kuhar, D.; Mowery, J.D.; Mitchell, A.; Gundersen-Rindal, D.E. Chromobacterium phragmitis sp. nov., isolated from estuarine marshes. Int. J. Syst. Evol. Microbiol. 2019. [CrossRef]

47. Menezes, C.; Tonin, M.; Corrêa, D.; Parma, M.; Melo, I.; Zucchi, T.; Destéfano, S.; Fantinatti-Garboggini, F. Chromobacterium amazonense sp. nov. isolated from water samples from the Rio Negro, Amazon, Brazil. Antonie Van Leeuwenhoek 2015, 107, 1057-1063. [CrossRef]

48. Hase, S.; Rietschel, E. The Chemical Structure of the Lipid a Component of Lipopolysaccharides from Chromobacterium violaceum NCTC 9694. Eur. J. Biochem. 1977, 75, 23-34. [CrossRef]

49. Vinogradov, E.; Brade, H.; Holst, O. The structure of the O-specific polysaccharide of the lipopolysaccharide from Chromobacterium violaceum NCTC 9694. Carbohydr. Res. 1994, 264, 313-317. [CrossRef]

50. Lima, D.C.; Nyberg, L.K.; Westerlund, F.; de Medeiros, S.R.B. Identification and DNA annotation of a plasmid isolated from Chromobacterium violaceum. Sci. Rep. UK 2018, 8, 5327. [CrossRef]

51. Batista, J.H.; Leal, F.C.; Fukuda, T.T.H.; Diniz, J.A.; Almeida, F.; Pupo, M.T.; Neto, J.F.S. Interplay between two quorum sensing-regulated pathways, violacein biosynthesis and VacJ/Yrb, dictates outer membrane vesicle biogenesis in Chromobacterium violaceum. Environ. Microbiol. 2020. [CrossRef]

52. Rooney, L.M.; Amos, W.B.; Hoskisson, P.A.; McConnell, G. Intra-colony channels in E. coli function as a nutrient uptake system. ISME J. 2020. [CrossRef]

53. Efthimion, M.; Corpe, W. Effect of Cold Temperatures on the Viability of Chromobacterium violaceum. Appl. Microbiol. 1969, 17, 169-175. [CrossRef] [PubMed]

54. Yoon, Y.; Lee, H.; Lee, S.; Kim, S.; Choi, K. Membrane fluidity-related adaptive response mechanisms of foodborne bacterial pathogens under environmental stresses. Food Res. Int. 2015, 72, 25-36. [CrossRef]

55. Clark, C.; Costa, M.S.; Sanchez, L.; Murphy, B. Coupling MALDI-TOF mass spectrometry protein and specialized metabolite analyses to rapidly discriminate bacterial function. Proc. National. Acad. Sci. USA 2018, 115, 201801247. [CrossRef]

56. Spring, S.; Merkhoffer, B.; Weiss, N.; Kroppenstedt, R.; Hippe, H.; Stackebrandt, E. Characterization of novel psychrophilic clostridia from an Antarctic microbial mat: Description of Clostridium frigoris sp. nov., Clostridium lacusfryxellense sp. nov., Clostridium bowmanii sp. nov. and Clostridium psychrophilum sp. nov. and reclassification of Clostridium laramiense as Clostridium estertheticum subsp. laramiense subsp. nov. Int. J. Syst. Evol. Microbiol. 2003, 53, 1019-1029. [CrossRef] [PubMed]

57. Pankratov, T.A.; Serkebaeva, Y.M.; Kulichevskaya, I.S.; Liesack, W.; Dedysh, S.N. Substrate-induced growth and isolation of Acidobacteria from acidic Sphagnum peat. ISME J. 2008, 2, 551-560. [CrossRef] [PubMed]

58. Li, Y.H.; Zhu, J.N.; Liu, Q.F.; Liu, Y.; Liu, M.; Liu, L.; Zhang, Q. Comparison of the diversity of root-associated bacteria in Phragmites australis and Typha angustifolia L. in artificial wetlands. World J. Microb. Biot. 2013, 29, 1499-1508. [CrossRef]

59. Kurniawan, A.; Yamamoto, T. Accumulation of $\mathrm{NH}^{4+}$ and $\mathrm{NO}^{3-}$ inside Biofilms of Natural Microbial Consortia: Implication on Nutrients Seasonal Dynamic in Aquatic Ecosystems. Int. J. Microbiol. 2019, 2019, 1-7. [CrossRef]

60. Prescott, R.; Decho, A. Flexibility and Adaptability of Quorum Sensing in Nature. Trends Microbiol. 2020, $28,436-444$. [CrossRef]

61. Yin, W.; Wang, Y.; Liu, L.; He, J. Biofilms: The Microbial “Protective Clothing” in Extreme Environments. Int. J. Mol. Sci. 2019, 20, 3423. [CrossRef]

62. Blanco, Y.; Rivas, L.; González-Toril, E.; Ruiz-Bermejo, M.; Moreno-Paz, M.; Parro, V.; Palacín, A.; Aguilera, Á.; Puente-Sánchez, F. Environmental parameters, and not phylogeny, determine the composition of extracellular polymeric substances in microbial mats from extreme environments. Sci. Total Environ. 2019, 650, 384-393. [CrossRef]

63. Kulichevskaya, I.; Guzev, V.; Gorlenko, V.; Liesack, W.; Dedysh, S. Rhodoblastus sphagnicola sp. nov., a novel acidophilic purple non-sulfur bacterium from Sphagnum peat bog. Int. J. Syst. Evol. Microbiol. 2006, 56, 1397-1402. [CrossRef] [PubMed] 
64. Imhoff, J. Bergey's Manual of Systematics of Archaea and Bacteria; Wiley: Hoboken, NJ, USA, 2015; pp. 1-11. [CrossRef]

65. Zheng, Y.; Dzakpasu, M.; Wang, X.; Zhang, L.; Ngo, H.H.; Guo, W.; Zhao, Y. Molecular characterization of long-term impacts of macrophytes harvest management in constructed wetlands. Bioresource Technol. 2018, 268, 514-522. [CrossRef] [PubMed]

66. Pankratov, T.A.; Tindall, B.J.; Liesack, W.; Dedysh, S.N. Mucilaginibacter paludis gen. nov., sp. nov. and Mucilaginibacter gracilis sp. nov., pectin-, xylan- and laminarin-degrading members of the family Sphingobacteriaceae from acidic Sphagnum peat bog. Int. J. Syst. Evol. Microbiol. 2007, 57, 2349-2354. [CrossRef] [PubMed]

67. Trappen, S.V.; Mergaert, J.; Eygen, S.V.; Dawyndt, P.; Cnockaert, M.C.; Swings, J. Diversity of 746 Heterotrophic Bacteria Isolated from Microbial Mats from Ten Antarctic Lakes. Syst. Appl. Microbiol. 2002, 25, 603-610. [CrossRef]

68. Kevbrina, M.V.; Okhapkina, A.A.; Akhlynin, D.S.; Kravchenko, I.K.; Nozhevnikova, A.N.; Gal'chenko, V.F. Growth of Mesophilic Methanotrophs at Low Temperatures. Microbiology 2001, 70, 384-391. [CrossRef]

69. Hahn, M.W.; Schmidt, J.; Koll, U.; Rohde, M.; Verbarg, S.; Pitt, A.; Nakai, R.; Naganuma, T.; Lang, E. Silvanigrella aquatica gen. nov., sp. nov., isolated from a freshwater lake, description of Silvanigrellaceae fam. nov. and Silvanigrellales ord. nov., reclassification of the order Bdellovibrionales in the class Oligoflexia, reclassification of the families Bacteriovoracaceae and Halobacteriovoraceae in the new order Bacteriovoracales ord. nov., and reclassification of the family Pseudobacteriovoracaceae in the order Oligoflexales. Int. J. Syst. Evol. Microbiol. 2017, 67, 2555-2568. [CrossRef]

70. Mishra, P.K.; Mishra, S.; Bisht, S.C.; Selvakumar, G.; Kundu, S.; Bisht, J.K.; Gupta, H.S. Isolation, molecular characterization and growth-promotion activities of a cold tolerant bacterium Pseudomonas sp. NARs9 (MTCC9002) from the Indian Himalayas. Biol. Res. 2009, 42, 305-313. [CrossRef]

71. Lee, K.C.Y.; Dunfield, P.F.; Stott, M.B. The Prokaryotes, Other Major Lineages of Bacteria and the Archaea; Springer: New York, NY, USA, 2014; pp. 447-458. [CrossRef]

72. Dedysh, S.N.; Panikov, N.S.; Tiedje, J.M. Acidophilic methanotrophic communities from Sphagnum peat bogs. Appl. Environ. Microb. 1998, 64, 922-929. [CrossRef]

73. Stackebrandt, E. The Prokaryotes, Actinobacteria; Springer: Berlin/Heidelberg, Germany, 2014; pp. 5-12. [CrossRef]

74. Lv, X.; Yu, J.; Fu, Y.; Ma, B.; Qu, F.; Ning, K.; Wu, H. A meta-analysis of the bacterial and archaeal diversity observed in wetland soils. Sci. World J. 2014, 2014, 437684. [CrossRef]

75. Oloo, F.; Valverde, A.; Quiroga, M.V.; Vikram, S.; Cowan, D.; Mataloni, G. Habitat heterogeneity and connectivity shape microbial communities in South American peatlands. Sci. Rep. UK 2016, 6, 25712. [CrossRef]

76. Cheng, C.; Ganta, R.R. Laboratory Maintenance of Ehrlichia chaffeensis and Ehrlichia canis and Recovery of Organisms for Molecular Biology and Proteomics Studies. Curr. Protoc. Microbiol. 2008, 9, 3A.1.1-3A.1.21. [CrossRef] [PubMed]

77. Zintl, A.; Moutailler, S.; Stuart, P.; Paredis, L.; Dutraive, J.; Gonzalez, E.; O'Connor, J.; Devillers, E.; Good, B.; OMuireagain, C.; et al. Ticks and Tick-borne diseases in Ireland. Ir. Vet J. 2017, 70, 4. [CrossRef] [PubMed]

78. Gray, J.S.; Dautel, H.; Estrada-Peña, A.; Kahl, O.; Lindgren, E. Effects of climate change on ticks and tick-borne diseases in Europe. Interdiscip. Perspect. Infect. Dis. 2009, 2009, 593232. [CrossRef] [PubMed]

Publisher's Note: MDPI stays neutral with regard to jurisdictional claims in published maps and institutional affiliations.

(C) 2020 by the authors. Licensee MDPI, Basel, Switzerland. This article is an open access article distributed under the terms and conditions of the Creative Commons Attribution (CC BY) license (http://creativecommons.org/licenses/by/4.0/). 